\title{
An upper-bound analytical model of blow-out for a shallow tunnel in sand considering the partial failure within the face
}

\author{
Pengfei Li, Keyi Chen, Fan Wang*, Zheng Li \\ The Key Laboratory of Urban Security and Disaster Engineering, Ministry of Education, Beijing University of \\ Technology, Beijing 100124, China \\ * Correspondence:wf04090@emails.bjut.edu.cn (F.W.)
}

\begin{abstract}
This paper proposes a three-dimensional analytical model of blow-out for a shallow tunnel in sand. Upper bound theorem is adopted to deduce the analytical solutions of limit support pressure, and a dimensionless parameter called partial failure ratio is defined to describe the range of partial failure within the tunnel face. A series of numerical simulations are carried out to analyse the limit support pressure and failure zone on the limit conditions. Finally, the analytical solutions including the partial failure ratio and limit support pressure obtained by the proposed model are compared with those obtained by the numerical simulation and the existing global failure model approaches. Results show that the proposed model in this paper can not only analyze the partial failure with better accuracy, but can also consider the global failure. The proposed model has more extensive applicability in analyzing the face stability of blow-out for a shallow shield tunnel.
\end{abstract}

Keywords: Shallow shield tunnel; Face stability; Partial failure; Limit analysis; Numerical simulation

Tunnelling and Underground Space Technology, Elsevier, 91 (2019)

https://doi.org/10.1016/j.tust.2019.05.019 


\section{Introduction}

During the construction of tunnel engineering, the excavation may weaken the tunnel face and cause face failure, especially for shallow tunnels (Yoo, 2002; Khezri et al., 2015; Patil et al., 2018; Ding et al., 2019). Tunnel excavation mainly refers to the closed-face case, like the open-face conventional tunneling or the shield tunneling (Pan et al., 2017). Conventional tunneling does not exert support pressure on tunnel face, but developing some auxiliary techniques, such as advance injection tubes, shed-pipe grouting, face bolts and umbrella arch system (Ocak et al., 2008; Aksoy et al., 2010; Maidl et al., 2013; Oke et al., 2014; Zhang et al., 2014; Anagnostou et al., 2015; Paternesi et al. 2017). These techniques generally improve the face stability by limiting the excessive deformation of the surrounding stratum, or reinforcing the rock or soil mass of the tunnel face.

Shield tunneling method has been more and more widely adopted in the construction of subway tunnels, for its advantages of higher security and slighter effect on complex urban environments. During the construction of shield tunnels, the face stability is a key issue to ensure the engineering safety (Liao et al., 2009; Sterpi et al., 2013; Jing et al., 2019). The chamber pressure is an effective support pressure to balance the water and soil pressure in front of tunnel face, and greatly influences the tunnel face stability (Zhou et al., 2013, Chen et al., 2018). If the applied chamber pressure is not sufficient to resist against the pressure from the surcharge and soil self-weight, active failure (collapse) occurs. On the other hand, blow-out, also referred to as passive failure, appears if the applied chamber pressure is high enough to 'push' the soil towards the ground surface (Klotz et al., 2006, Mollon et al., 2011). In practical engineering, the blow-out, which is triggered by the high chamber pressure, is very common in shallow shield tunnels and results in huge economic losses. Therefore, researches on blow-out of shield tunnel face are worthy of carrying out.

Scholars have investigated the tunnel face stability mainly through three approaches: theoretical analysis, experimental test and numerical simulation. However, most of the researches were just available for the collapse failure (Broms et al., 1967; Davis et al., 1980; Murayama, 1996; Subrin et 
al., 2002; Fang et al., 2012, 2015). There were few studies on the blow-out, that is, the blow-out in front of the tunnel face. As for the theoretical analysis, a reasonable failure mode of soil can be used to describe more accurately the limit support pressure. Thus, the assumption of the failure model in front of tunnel face has been widely taken into account to analyze the tunnel face stability. Leca and Dormieux (1990) proposed a blow-out mechanism composed of a single conical block outcropping at the ground surface for very shallow tunnels in weak soils. Based on the model of Leca and Domreiux (1990), Soubra (2000) improved the single-block into a new blow-out failure mechanism consisting of two truncated rigid cones and a log spiral, and the relationship between the cohesion coefficient $N_{c}$ and the surcharge coefficient $N_{s}$ was given. Then, Soubra et al. (2008) improved the failure region above into five truncated rigid cones, which further optimized the results of the upper bound solution. Mollon et al. (2011) employed the spatial discretization technique and presented a rotational failure mechanism delimited by two logarithmic spirals in the central vertical plane of the tunnel, which made it possible to involve the entire circular tunnel face. Senent et al. (2013) used limit analysis method and nonlinear Hoek-brown failure criterion respectively to investigate the failure of tunnel face and crown. Chen et al. (2013) studied the blow-out failure mode under the sandy soil layer and modified the prism in the traditional three-dimensional wedge model to a chamfered platform with a certain inclination angle. Compared to the limit equilibrium methods (Horn, 1961; Jancsecz et al., 1994; Anagnostou et al., 1996; Broere, 2001), the limit analysis methods have a strictly theoretical basis and provide better results (Han et al., 2016). In addition, the numerical approach (Li et al., 2009; Wong et al., 2009) and experimental approach (Li et al., 2007; Wong, 2012) were also widely used in the analysis of blow-out.

At present, it has been concluded from some researches that there exists a gradual evolution process from partial failure to global failure within the tunnel face when blow-out caused by the excessive support pressure occurs. Global failure means that the failure range within the tunnel face covers the entire tunnel face, while partial failure area includes only the upper part of the tunnel face. 
Dias et al. (2008) performed a series of numerical simulation by FLAC ${ }^{3 \mathrm{D}}$ for a shallow tunnel and concluded that the partial failure rather than global failure was firstly observed within the tunnel face when the blow-out occurs. Li et al. (2009) obtained the displacement contour of tunnel face in blowout for the Shanghai Yangtze River Tunnel by numerical simulation. It was shown that the conspicuous displacement occurs in the upper part of the tunnel face, while the displacement was hardly observed near the tunnel invert. Thus, the partial failure within the tunnel face of shallow tunnels is a significant problem that needs to pay much more attention. However, most of the existing researches for tunnel face stability all focused on the global failure within the whole tunnel face. The analytical solution for partial failure in blow-out was seldom studied.

This paper aims at proposing an analytical model of blow-out for a shallow tunnel in sand under drained condition to analyse the partial failure within the tunnel face. The analytical solution of limit support pressure is derived based on the upper-bound theorem. Then, a series of numerical simulations are performed to obtain the limit support pressure and failure zone in front of the tunnel face. Finally, the analytical solutions including the partial failure ratio and limit support pressure obtained by the proposed model are compared with those obtained by the numerical simulation and existing approaches.

\section{Proposed model}

\subsection{Problem description}

Based on the single conical block mechanism proposed by Leca and Dormieux (1990), Soubra et al. (2008) presented a translational kinematically admissible failure mechanisms composed of several truncated rigid cones. These rigid cones with an opening angle $2 \varphi$ are reversed and the mechanism always outcrops. Although this model has been widely used to analyze the blow-out case, it is not capable to the analysis of partial failure within the tunnel face. Therefore, as indicated in Fig. 1, a failure model is established to analyse the partial failure in blow-out within the shallow tunnel face in dry sand. This model further improves the model proposed by Soubra et al. (2008). Only five 
blocks are necessary for the blow-out mechanism since an increase in the number of blocks improves the solutions by a few percent. The soil is assumed to be homogeneous, isotropic and characterized by the Mohr-Coulomb yield criterion.

As shown in Fig. 1, a tunnel of diameter $D$ excavated under a cover depth $C$ is considered. A surcharge $\sigma_{s}$ is applied on the ground surface, and a uniform pressure $\sigma_{T}$ is imposed on the tunnel face (Ibrahim et al., 2015, Leca et al., 1990, Li et al., 2009, Mollon et al., 2013, Soubra et al., 2008). Meanwhile, a dimensionless parameter called partial failure ratio $(\eta=d / D)$ is defined to describe the range of partial failure within the tunnel face. Specifically, the blow-out case with global failure can be taken into account when $\eta=1$ is applied; when $0<\eta<1$, the blow-out case with partial failure occurs with a partial failure ratio $\eta$.

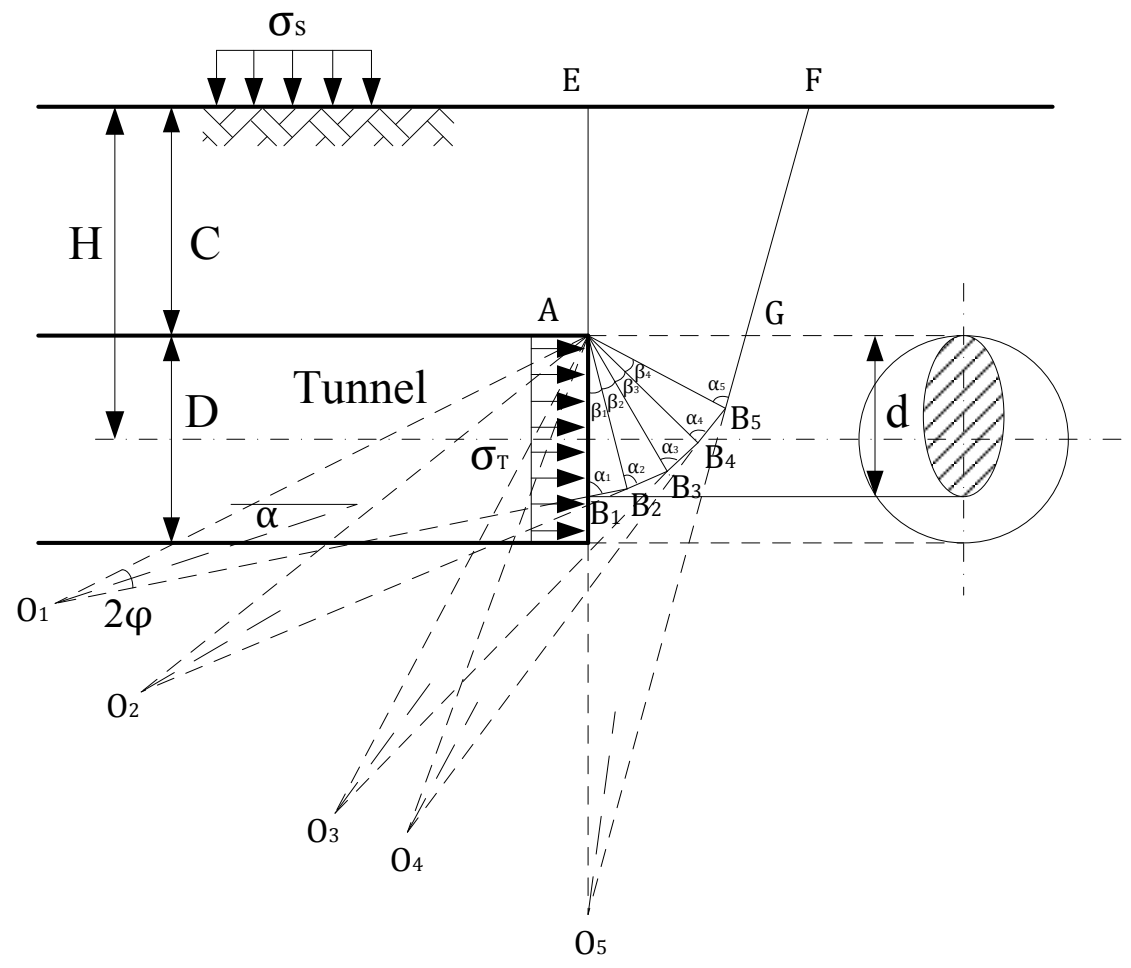

Fig. 1. The new 3D partial failure mechanism. 


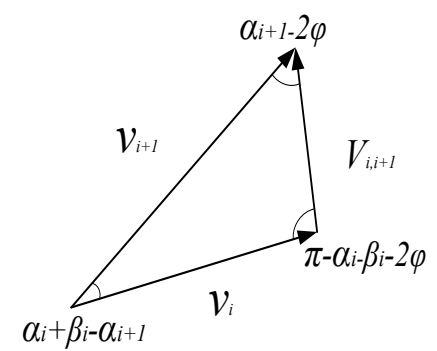

Fig. 2. The velocity field of the new 3D failure mechanism.

\subsection{Analytical solutions}

\subsubsection{Geometric properties}

(1) Angle parameters

According to the geometric properties, $\alpha_{\mathrm{i}}$ (for $1 \leq i \leq 5$ ) can be given by

$$
\begin{gathered}
\alpha_{1}=\frac{\pi}{2}-\alpha+\varphi \\
\alpha_{2}=\frac{\pi}{2}-\beta_{1}+\alpha+\varphi \\
\alpha_{3}=\frac{\pi}{2}+\beta_{1}-\beta_{2}-\alpha+\varphi \\
\alpha_{4}=\frac{\pi}{2}-\beta_{1}+\beta_{2}-\beta_{3}+\alpha+\varphi \\
\alpha_{5}=\frac{\pi}{2}+\beta_{1}-\beta_{2}+\beta_{3}-\beta_{4}-\alpha+\varphi
\end{gathered}
$$

(2) Length parameters

The intersection of the first block and tunnel face is an ellipse with a long axis of $A B_{1}$ in vertical direction. It can be known that:

$$
A B_{1}=d
$$

The intersections of adjacent blocks are also ellipses with a long axis of $A B_{i}$ that are calculated as:

$$
A B_{i}=\frac{\sin \alpha_{i-1}}{\sin \left(\alpha_{i-1}+\beta_{i-1}\right)} A B_{i-1} \quad(i=2,3,4,5)
$$

The busbar of the truncated cone $A B_{i} O_{i}$ is 


$$
A O_{i}=\frac{\sin \alpha_{i}}{\sin 2 \varphi} A B_{i} \quad(i=1,2,3,4,5)
$$

The height of the truncated cone $A B_{i} O_{i}$ and $E F O_{5}$ is obtained by

$$
\begin{gathered}
h_{i}=A O_{i} \sin \left(\alpha_{i}-2 \varphi\right) \quad(i=1,2,3,4,5) \\
\mathrm{h}_{6}=C+A O_{5} \cos \left(\sum_{i=1}^{4} \beta_{i}-\alpha_{5}+2 \varphi\right)
\end{gathered}
$$

(3) Area and volume parameters

The area $A_{l}$ of the ellipse which intersects between the first block and tunnel face is as follows:

$$
A_{1}=\pi \frac{d^{2}}{4} \sqrt{1-\frac{\sin ^{2} \alpha}{\cos ^{2} \varphi}}
$$

In addition, the area $A_{\mathrm{i}}$ of the ellipse which intersects between the two adjacent blocks is described as:

$$
A_{i}=\pi \frac{A B_{i}^{2}}{4} \sqrt{1-\frac{\sin ^{2} \theta_{i}}{\cos ^{2} \varphi}} \quad(i=2,3,4,5)
$$

The elliptical area $A_{6}$ where the last truncated cone intersects the ground is denoted as:

$$
A_{6}=\pi \frac{E F^{2}}{4} \sqrt{1-\frac{\sin ^{2} \theta_{6}}{\cos ^{2} \varphi}}
$$

The volume (for $1 \leq i \leq 5$ ) and lateral area $S_{\mathrm{i}}($ for $1 \leq i \leq 5$ ) of the rigid truncated elliptical cone $i$ are expressed as:

$$
\begin{gathered}
V_{i}=\frac{1}{3}\left(A_{i+1} h_{i+1}-A_{i} h_{i}\right) \quad(i=1,2,3,4,5) \\
S_{1}=A_{2} \frac{\cos \theta_{2}}{\sin \varphi}-A_{1} \frac{\cos \alpha}{\sin \varphi} \\
S_{i}=A_{i+1} \frac{\cos \theta_{i+1}}{\sin \varphi}-A_{i} \frac{\cos \theta_{i}}{\sin \varphi} \quad(i=2,3,4,5)
\end{gathered}
$$

(4) Related characteristic parameters 


$$
\begin{gathered}
\theta_{1}=\alpha \\
\theta_{i}=\beta_{i-1}-\theta_{i-1} \quad(i=2,3,4,5) \\
\theta_{6}=\alpha_{5}-\sum_{i=1}^{4} \beta_{i}-\varphi \\
E F=\left(\frac{C}{\cos \left(\alpha_{5}-\sum_{i=1}^{4} \beta_{i}-2 \varphi\right)}+A O_{5}\right) \frac{\sin 2 \varphi}{\sin \left(\frac{\pi}{2}-\alpha_{5}+\sum_{i=1}^{4} \beta_{i}\right)}
\end{gathered}
$$

(5) Velocity relationship

The velocity hodograph is given in Fig. 2. The velocities relationships are determined as follows:

$$
\begin{gathered}
v_{i+1}=v_{i} \frac{\sin \left(\alpha_{i}-\beta_{i}-2 \varphi\right)}{\sin \left(\alpha_{i+1}-2 \varphi\right)} \quad(i=1,2,3,4) \\
v_{i, i+1}=v_{i} \frac{\sin \left(\alpha_{i}+\beta_{i}-\alpha_{i+1}\right)}{\sin \left(\alpha_{i+1}-2 \varphi\right)} \quad(i=1,2,3,4)
\end{gathered}
$$

The angle $\psi_{\mathrm{i}}($ for $1 \leq i \leq 5)$ between velocity $v_{i}$ (for $\left.1 \leq i \leq 5\right)$ and vertical direction are obtained as follows:

$$
\begin{gathered}
\psi_{1}=\alpha_{1}-\varphi \\
\psi_{i}=\alpha_{i}-\sum_{i=1}^{i-1} \beta_{i}-\varphi \quad(i=2,3,4,5)
\end{gathered}
$$

\subsubsection{Limit support pressure}

The power $P_{\sigma_{T}}$ of the support pressure, the power $P_{\sigma_{s}}$ of the surcharge, the power $\mathrm{P}_{\gamma}$ of the soil unit weight and the power $P_{\mathrm{e}}$ of external loads can be calculated by Eqs. (25 28)

$$
\begin{gathered}
P_{\sigma_{T}}=\sigma_{T} \mathrm{~A}_{1} v_{1} \sin \left(\alpha_{1}-\varphi\right) \\
P_{\sigma_{s}}=-\sigma_{s} \mathrm{~A}_{6} v_{5} \cos \psi_{5} \\
P_{\gamma}=-\gamma\left[\sum_{i=1}^{4} v_{i} V_{i} \cos \psi_{i}+v_{5} V_{5} \cos \psi_{5}\right] \\
P_{e}=P_{\sigma_{T}}+P_{\sigma_{s}}+P_{\gamma}
\end{gathered}
$$


The relationship between the dissipation power $P_{v}$ and cohesion c of the blow-out region is denoted as

$$
P_{v}=c\left[\sum_{i=1}^{4} v_{i} \mathrm{~S}_{i}+v_{5} \mathrm{~S}_{5}+\sum_{i=1}^{4} A_{i+1} v_{i, \mathrm{i}+1}\right] \cos \varphi
$$

According to the upper bound theorem of the limit analysis method, the condition for the stability of the tunnel face is

$$
P_{e} \leq P_{v}
$$

By Eqs. (25), (28) and (30), the limit support pressure is denoted as

$$
\sigma_{T}=\frac{P_{v}-P_{\gamma}-P_{\sigma_{s}}}{\mathrm{~A}_{1} v_{1} \sin \left(\alpha_{1}-\varphi\right)}
$$

To be more concise, the support pressure function of the model is determined as follows:

$$
\sigma_{T}=N_{\gamma} \cdot \gamma D+c N_{c}+\sigma_{s} N_{s}
$$

where $N_{s}, N_{\gamma}$ and $N_{c}$ are used as non-dimensional coefficients to indicate the influence of surcharge, the soil weight and cohesion on the limit support pressure, respectively.

$$
\begin{gathered}
N_{s}=\frac{A_{6}}{A_{1}} \times \frac{\sin \left(2 \beta_{2}+2 \beta_{4}+\alpha\right)}{\cos \alpha} \times \frac{v_{5}}{v_{1}} \\
N_{c}=\frac{\left(N_{s}-1\right)}{\tan \varphi} \\
N_{\gamma}=\frac{\left(N_{1}+N_{2}+N_{3}+N_{4}+N_{5}\right)}{D \mathrm{~A}_{1} \cos \alpha} \\
N_{1}=V_{1} \sin \alpha \\
N_{2}=\frac{v_{2}}{v_{1}} \times V_{2} \times \sin \left(2 \beta_{1}-\alpha\right) \\
N_{3}=\frac{v_{3}}{v_{1}} \times V_{3} \times \sin \left(2 \beta_{2}+\alpha\right)
\end{gathered}
$$




$$
\begin{aligned}
& N_{4}=\frac{v_{4}}{v_{1}} \times V_{4} \times \sin \left(2 \beta_{1}+2 \beta_{3}-\alpha\right) \\
& N_{5}=\frac{v_{5}}{v_{1}} \times V_{5} \times \sin \left(2 \beta_{2}+2 \beta_{4}+\alpha\right)
\end{aligned}
$$

From the equations above, it is found that the limit support pressure is determined by the limit partial failure ratio $\eta$, the angle parameters $\alpha$ and $\beta_{i}(i=1,2,3,4)$. The optimal solution of limit support pressure can be obtained by a mathematically.

\section{Numerical simulations by using FLAC ${ }^{3 D}$}

\subsection{Numerical models}

The analysis above shows that the factors affecting the limit support pressure consist of tunnel covered depth $C$, tunnel diameter $D$ and friction angle $\varphi$. A series of numerical models performed by the program FLAC $^{3 \mathrm{D}}$ are established to analyse the influence of these factors and verify the analytical model. Twelve cases, as shown in Table 1, are simulated. For the sake of simplicity, it is assumed that the soil is cohesionless $(c=0)$ and its unit weight $\gamma$ is $18 \mathrm{kN} / \mathrm{m}^{3}$. Also, the surcharge is assumed to be zero.

\section{Table 1}

\begin{tabular}{|c|c|c|c|}
\hline Cases & $\begin{array}{l}\text { Covered depth } \\
\qquad \mathrm{C}(\mathrm{m})\end{array}$ & $\begin{array}{c}\text { Tunnel diameter } \\
\text { D (m) }\end{array}$ & $\begin{array}{c}\text { Friction angle } \\
\varphi\left({ }^{\circ}\right)\end{array}$ \\
\hline Case 1 3 & $3,6,9$ & 6 & 15 \\
\hline Case 4 8 & 3 & $8,10,12,14,16$ & 15 \\
\hline Case 9 12 & 3 & 6 & $20,25,30,35$ \\
\hline
\end{tabular}

Calculation parameters.

In this section, numerical analyses were conducted by a finite difference computer program FLAC $^{3 \mathrm{D}}$ are reviewed to calculate limit passive pressure and verify the partial failure proposed in this paper. As shown in Fig. 3, considering the symmetry, the model shows only half of the circular tunnel cut longitudinally along the central axis. The boundary conditions of the model are given as follows: the ground surface is free; the lateral displacement boundaries are fixed in the normal direction and 
the displacement boundaries at the bottom are fixed in both the horizontal and vertical directions (Li et al. 2015). The longitudinal length of the model is $80 \mathrm{~m}$ and the transverse length is 5 times tunnel diameter $(5 D)$. The total height of the model is equal to $C+6 D$. The three-dimensional model were determined by using non-uniform grids, including 104871 nodes and 100320 elements (for $C / D=1.0$ ). The model of the numerical simulation is characterized by a Mohr-Coulomb yield criterion. The Poisson's ratio of soil layer is set as 0.35 and the bulk modulus is set as $80 \mathrm{MPa}$.

The detailed steps of numerical simulation are described as follows:

(1) Establishing the original sand layer model.

(2) A simplified single-step excavation scheme, which has been successfully adopted in many previous researches (Gioda and Swoboda, 1999), is simulated to focus on the analysis of tunnel face stability. In this paper, $30 \mathrm{~m}$ is excavated in one step when performing the numerical simulation (see Fig. 3). At the same time, the fixed constraints are imposed on each node around the tunnel perimeter that has been excavated.

(3) Then the support pressure, which equal to the initial ground horizontal stress for the center of the tunnel, is applied on the tunnel face. By increasing the support pressure applied on the tunnel face gradually, the relationship curves between the support pressure and the horizontal displacement of the central point within the tunnel face can be plotted.

(4) When the support pressure applied on tunnel face increases to a certain value, the horizontal displacement of the central point within the tunnel face increases sharply. At this moment, the limit support pressure for the blow-out case is obtained. 


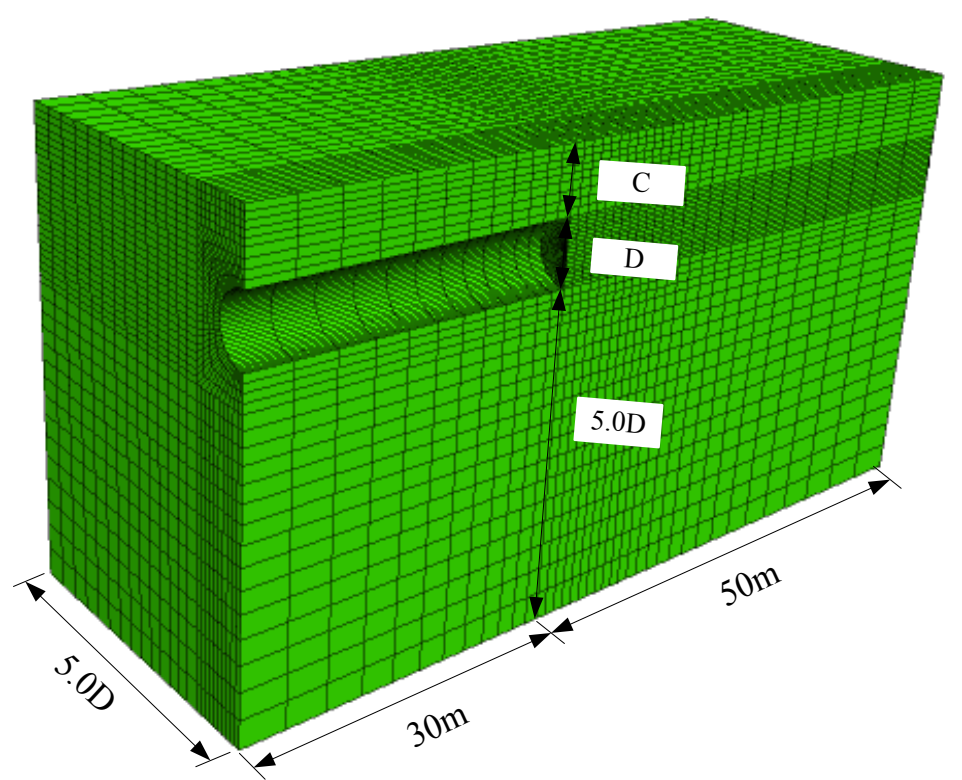

Fig. 3. Numerical model.

\subsection{Numerical results}

\subsubsection{Limit support pressure}

Fig. 4 shows the relationship between the support pressure ratio $P / P_{0}$ (the ratio of the specified face support pressure to the initial ground horizontal stress for the center of the tunnel) and the horizontal displacement of the central point within tunnel face for the 12 cases are shown in Table 1. It can be seen that the horizontal displacement of the central point within the tunnel face increases with the increase of the support pressure $P$. When $P$ increase to a certain value, the horizontal displacement of the central point does not converge and increases dramatically. At this time, the soil is considered to reach the limit state and the support pressure $P$ is expressed as $\sigma_{\mathrm{T}}$. As shown in Fig. 4(a), the values of $\sigma_{\mathrm{T}} / P_{0}$ increase from 3.31 to 5.80 with the increase of buried depth $C$ in the case of the same other conditions. Similarly, from Fig. 4(b), it can be seen that with the increase of diameter $D$, the values of $\sigma_{\mathrm{T}} / P_{0}$ increase from 1.70 to 2.76 , while those increase from 5.34 to 21.60 with the increase of friction angle $\varphi$ in Fig. 4(c). Therefore, the deeper depth $C$, the smaller tunnel diameter $D$ and the higher friction angle $\varphi$, corresponding to greater limit support pressure ratios. Moreover, it appears that the influence of tunnel depth and friction angle on the limit support pressure ratios is more obvious. The following discussion will focus on the effects of the three factors of the cover 
depth $C$, the tunnel diameter $D$ and the friction angle $\varphi$ on partial failure ratio and the limit support pressure.

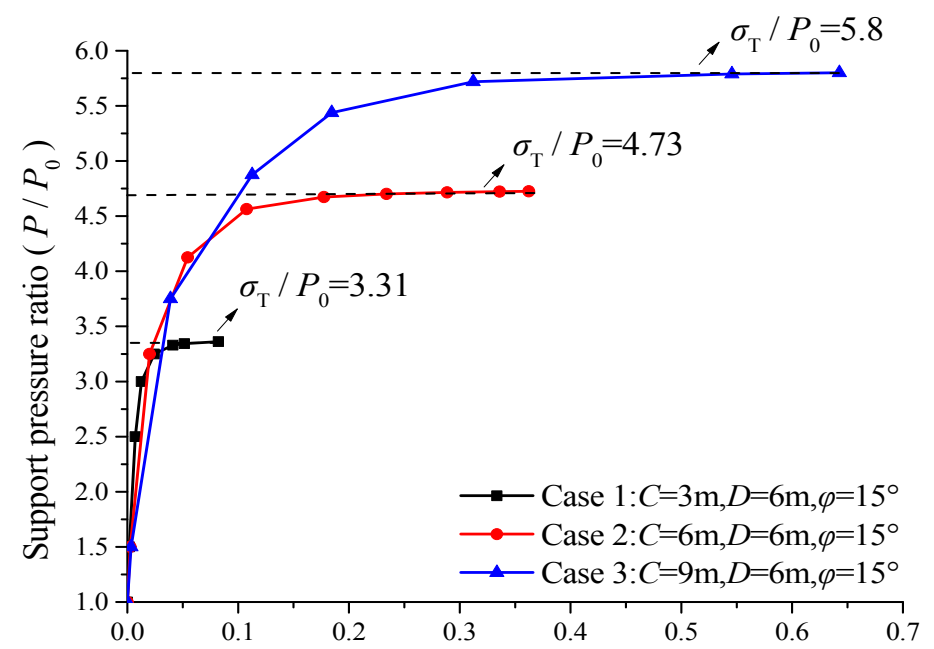

Horizontal displacement of the central point within tunnel face (m)

(a)

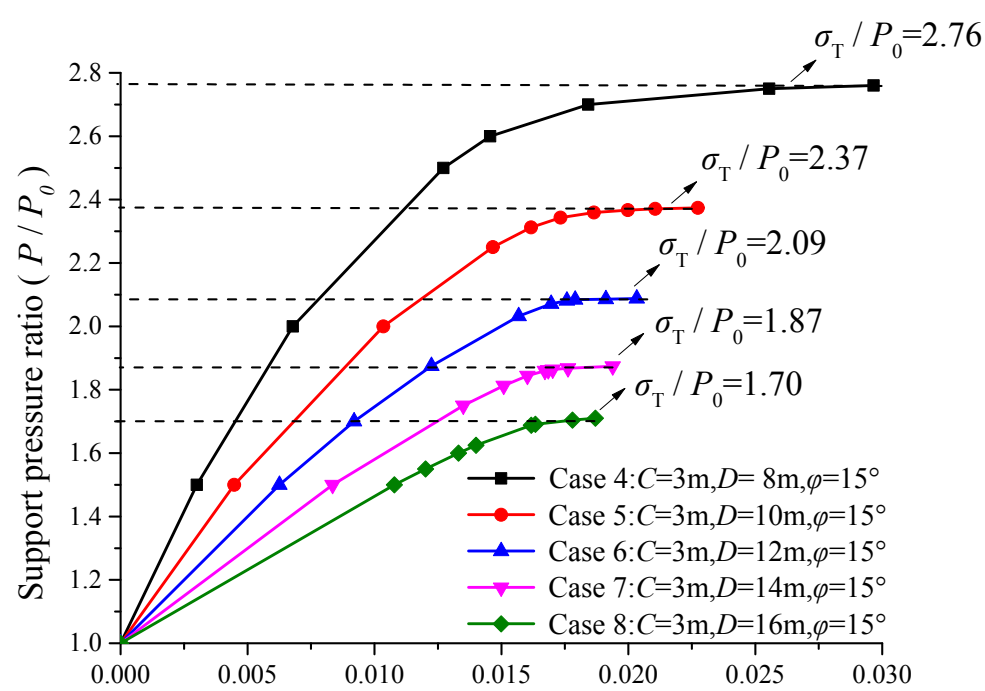

Horizontal displacement of the central point within tunnel face (m)

(b) 


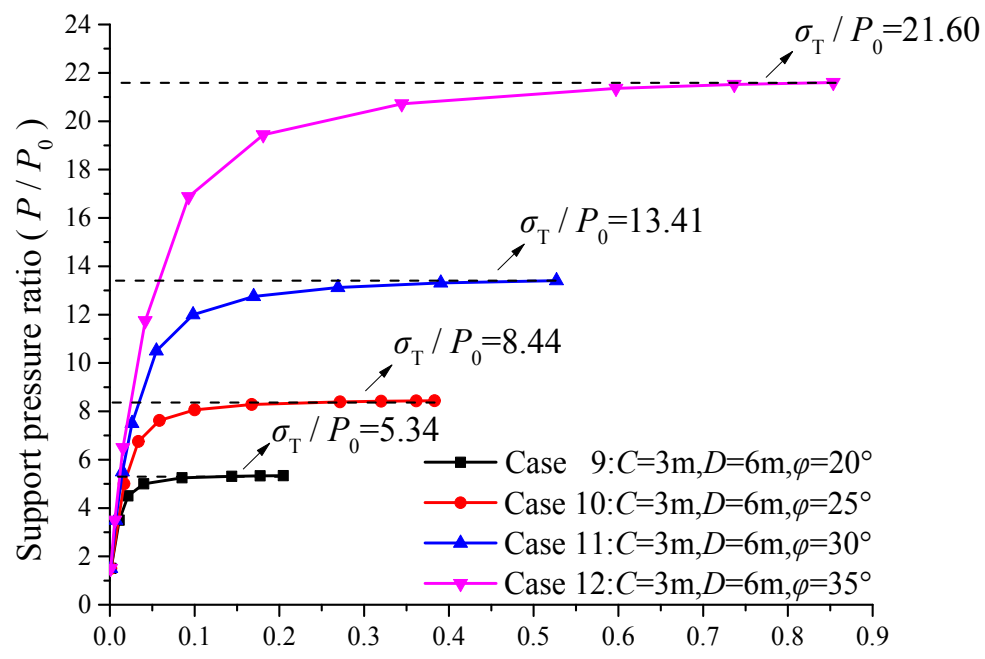

Horizontal displacement of the central point within tunnel face $(\mathrm{m})$

(c)

Fig. 4. Relationship between $P / P_{0}$ and horizontal displacement.

\subsubsection{Failure zone on the limit conditions}

As shown in Fig. 5, the failure mechanism in Case 9, Case 2, Case 4 and Case 5 could be observed in another way by plotting the horizontal displacement for several monitored points along the central vertical axis of the tunnel face. In Fig. $5(\mathrm{a})$, for Case $9\left(C=3 \mathrm{~m}, D=6 \mathrm{~m}, \varphi=20^{\circ}\right)$, the upper part of tunnel face close to the crown shows larger displacements, while the displacements in the lower part near the invert are relatively small. The inflection point between the upper part blow-out and lower part blow-out can be determined by the double tangent line, and the range from the inflection point to the crown is the partial failure area $(\eta=0.607)$. As can be seen from Fig. 5 (b), for Case $2\left(C=6 \mathrm{~m}, D=6 \mathrm{~m}, \varphi=15^{\circ}\right)$, all the nodes within tunnel face show large displacements. Although the horizontal displacements in the upper part of tunnel face is greater than those in the lower part, it is impossible to plot a double tangent line like Case 9. In other words, the failure area within tunnel face is the whole face. For Case $4\left(C=3 \mathrm{~m}, D=8 \mathrm{~m}, \varphi=15^{\circ}\right)$ and Case $5(C=3 \mathrm{~m}, D=10 \mathrm{~m}$, $\varphi=15^{\circ}$ ), it is clearly seen that the curves shown in Figs. 5(c) and (d) are the same as that in Fig. 5(a). That is to say, the partial failure occurs within the tunnel face for Case 4 and Case 5. 


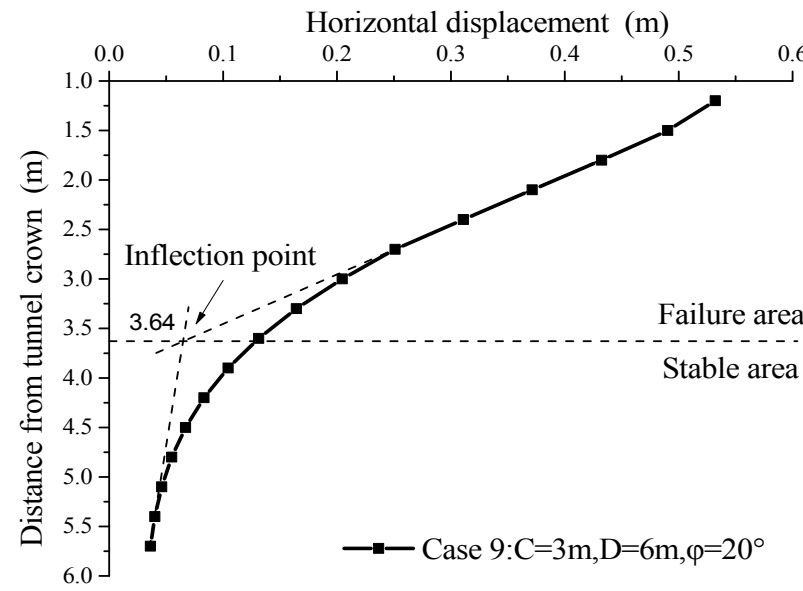

(a)

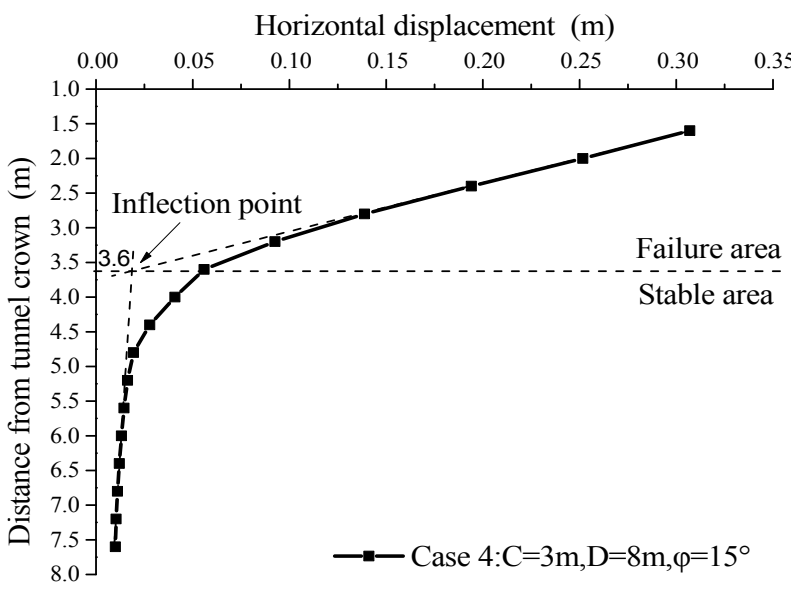

(c)

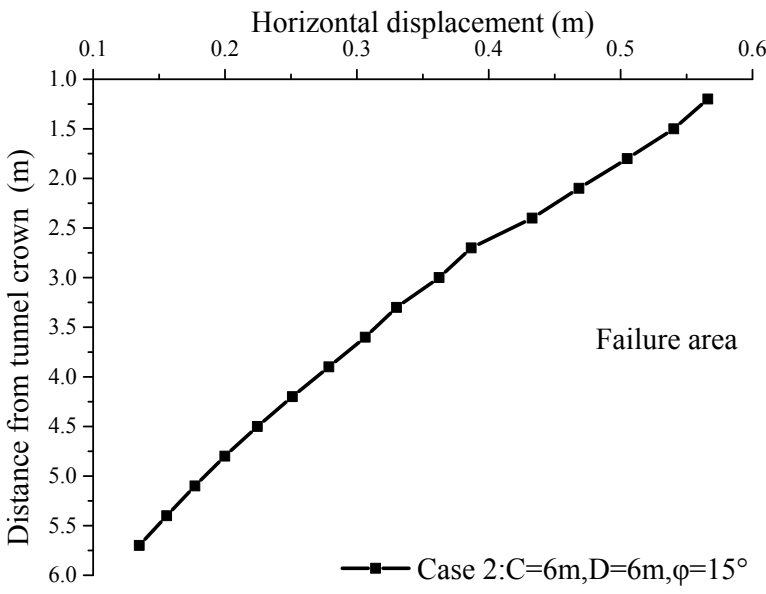

(b)

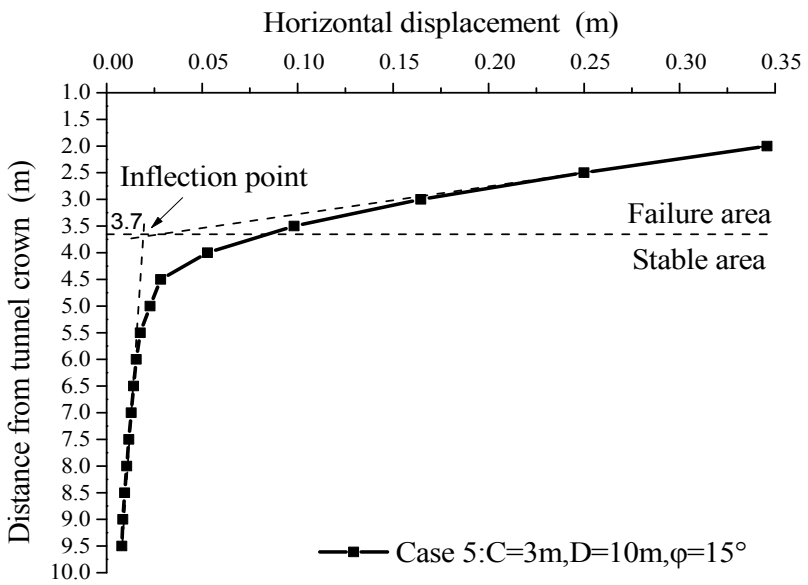

(d)

Fig. 5. Horizontal displacement curve of tunnel face obtained by numerical simulation.

Fig. 6 shows the displacement contours in limit conditions for Case 9, Case 2, Case 4 and Case5. For Case $9\left(C=3 \mathrm{~m}, D=6 \mathrm{~m}, \varphi=20^{\circ}\right)$, as observed in Fig. 6(a), the values of the isoline greater than $0.15 \mathrm{~m}$ change uniformly, while the values of the contour line less than $0.15 \mathrm{~m}$ change significantly. According to the analysis of Zhang et al. (2015), "the position within a sudden increase gradient can be defined as the boundary strip of the failure zone." If the isoline with displacement value of $0.15 \mathrm{~m}$ is taken as the boundary strip of partial failure, the distance from the boundary strip to tunnel crown within tunnel face is about $3.6 \mathrm{~m}$. This value is approximately consistent with the result obtained from Fig. 5 (a). The comparison is also shown in Fig. 6(a). The red line represents the boundary of the failure zone provided by numerical simulation, and the black line represents the failure zone boundary of proposed model. Similarly, for Case $2\left(C=6 \mathrm{~m}, D=6 \mathrm{~m}, \varphi=15^{\circ}\right)$ 、 Case $4\left(C=3 \mathrm{~m}, D=8 \mathrm{~m}, \varphi=15^{\circ}\right)$ 
and Case $5\left(C=3 \mathrm{~m}, D=10 \mathrm{~m}, \varphi=15^{\circ}\right)$, the boundary strip of partial failure and the distance from the boundary strip to tunnel crown are shown in Fig. 6(b)(c)(d).

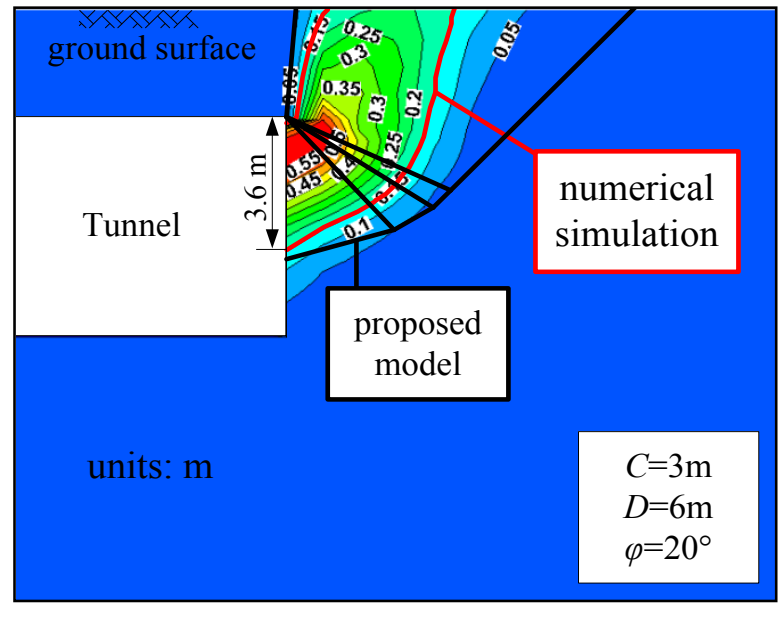

(a) Case 9

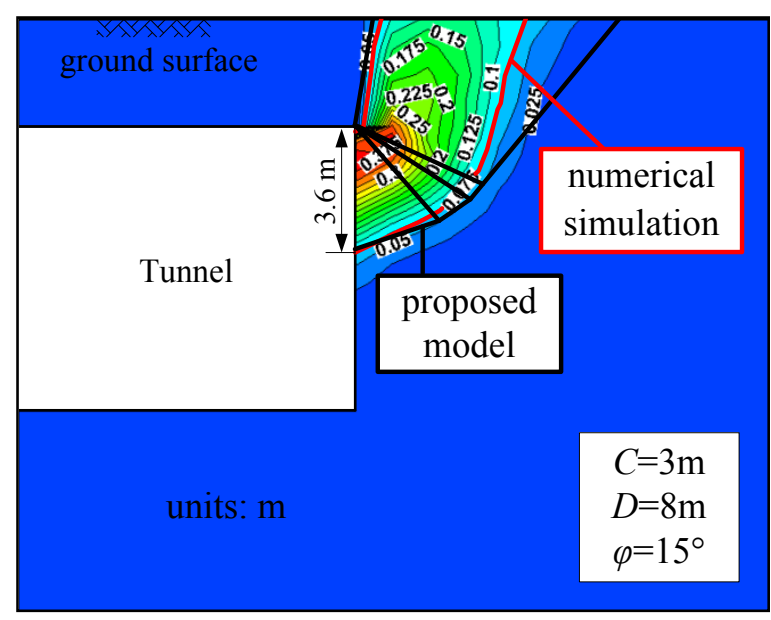

(c) Case 4

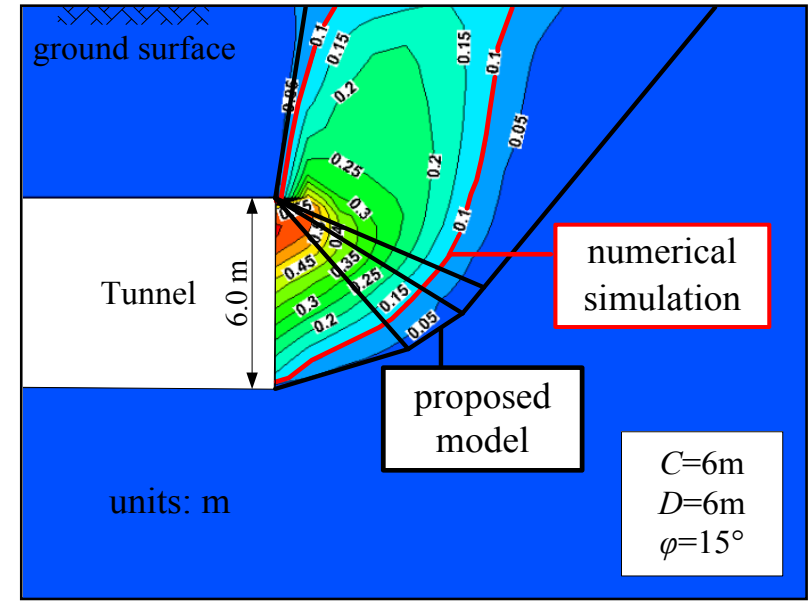

(b) Case 2

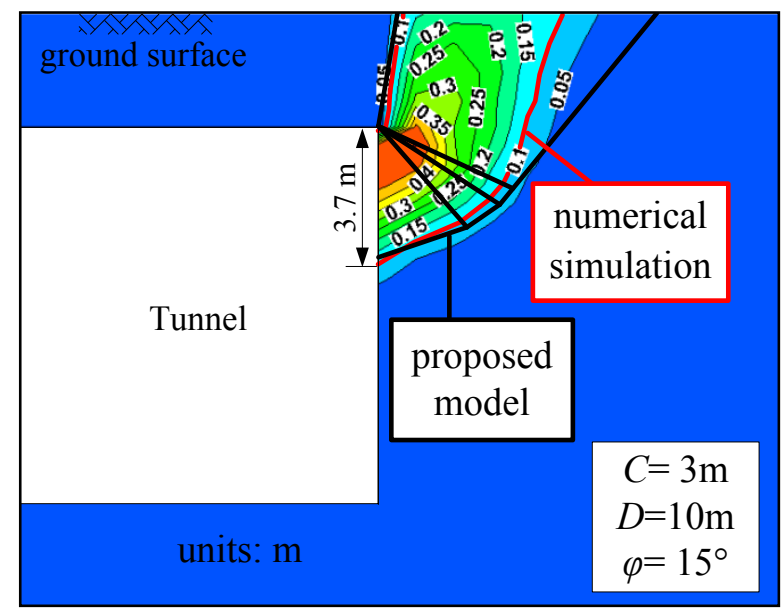

(d) Case 5

Fig. 6. Displacement contours in limit conditions.

Fig. 7 shows the displacement of ground surface in limit conditions for various friction angles $(C=3 \mathrm{~m}, D=6 \mathrm{~m})$. The displacements of ground surface in limit conditions occurs in the range of $2.0 D$ (12m) ahead of the shield. Moreover, the maximum outcrop point gradually approaches toward the tunnel face with the increase of friction angle. 


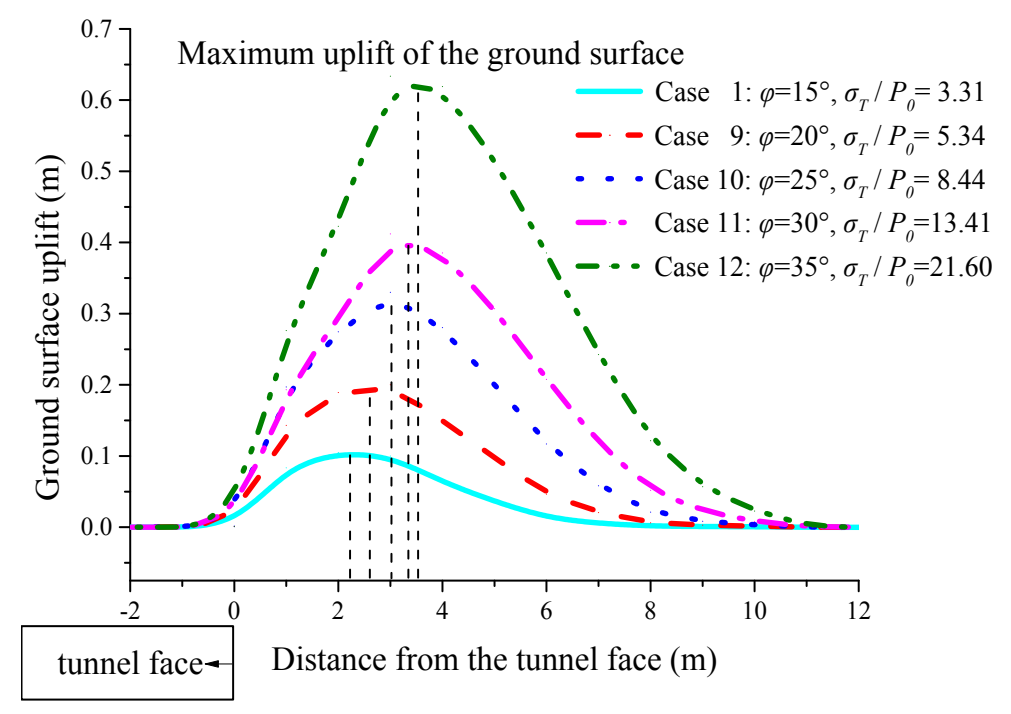

Fig. 7. The displacement of ground surface $(C / D=0.5)$.

\section{Parametric studies}

\subsection{Partial failure ratio}

\subsubsection{Effect of cover depth $(C)$}

For the invariant tunnel diameter $D$ and friction angle $\varphi$, the relationship between the cover depth $C$ and the partial failure ratio $\eta$ is described in Fig. 8. The partial failure ratio $\eta$ obtained by the proposed model increases linearly at first and then remains constant with the increase of $C / D$. During the increasing phase, partial failure occurs with $\eta<1$. When $C / D$ increase to a certain value, the partial failure ratio $\eta$ reach to 1.0, namely, global failure occurs. The critical cover depth at which the failure mechanism within tunnel face evolves from partial failure to global failure is approximately 1 times the tunnel diameter. That means there will be no partial failure when $C / D$ is greater than 1.0 . In addition, the results obtained by numerical simulation show the similar rule and match well with the theoretical model. 


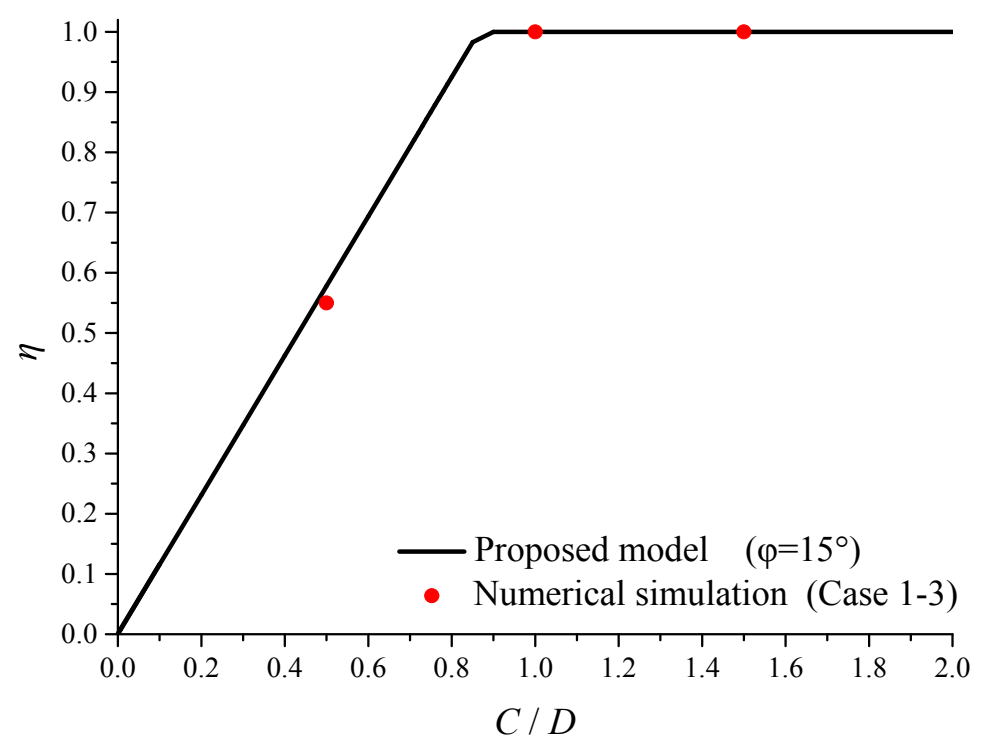

Fig. 8. Comparison between numerical simulation and theoretical model $\left(D=6 \mathrm{~m}, \varphi=15^{\circ}\right)$.

4.1.2. Effect of tunnel diameter $(D)$

For the case where the cover depth $C$ and friction angle $\varphi$ are constant, the relationship between the long-axis size $d$ of the partial failure region and tunnel diameter $D$ is shown in Fig. 9(a). It can be seen that $d$ obtained by the proposed model remains constant with the increase of tunnel diameter $D$, while $d$ obtained by the numerical simulation increases slightly. In addition, Fig. 9(b) shows the relationship between the partial failure ratio $\eta$ and tunnel diameter $D$. It can be found that $\eta$ gradually decreases regardless of analytical solutions and numerical solutions.

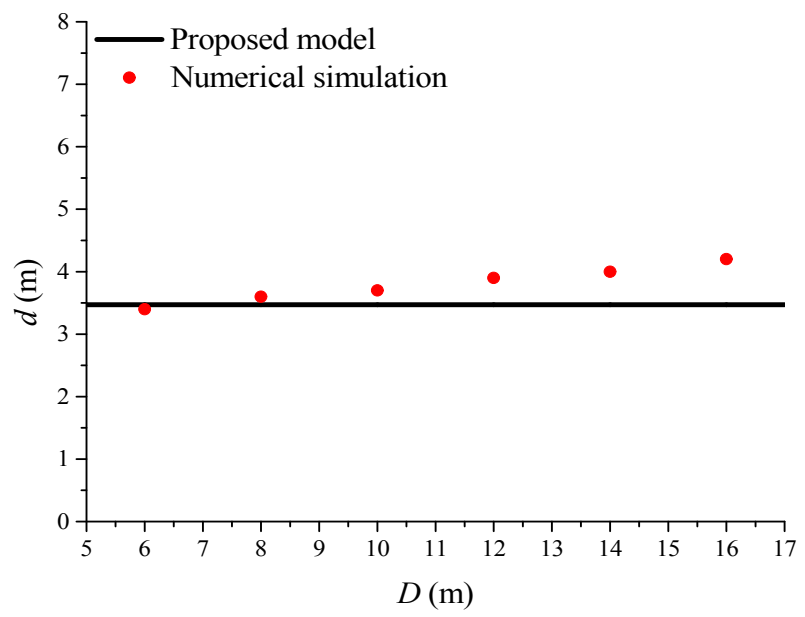

(a) Relationship between $d$ and $D$

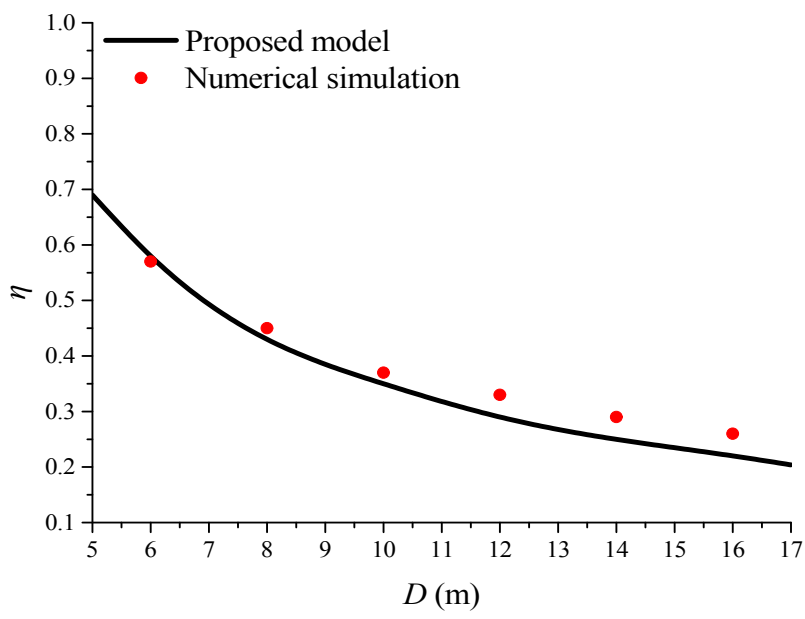

(b) Relationship between $\eta$ and $D$

Fig. 9. Effects of $D$ on $\eta$ and $d\left(C=3 \mathrm{~m}, \varphi=15^{\circ}\right)$. 
Note that, the rule between $\eta$ and $D$ described in Fig. 9(b) occurs because the cover depth ratio $C / D$ changes. As shown in Fig. 10 , if $C / D$ is fixed to a constant value (for example, $C / D=0.5$ ), the partial failure ratios $\eta$ obtained by the proposed model and numerical simulation are all basically unchanged as the tunnel diameter $D$ increases.

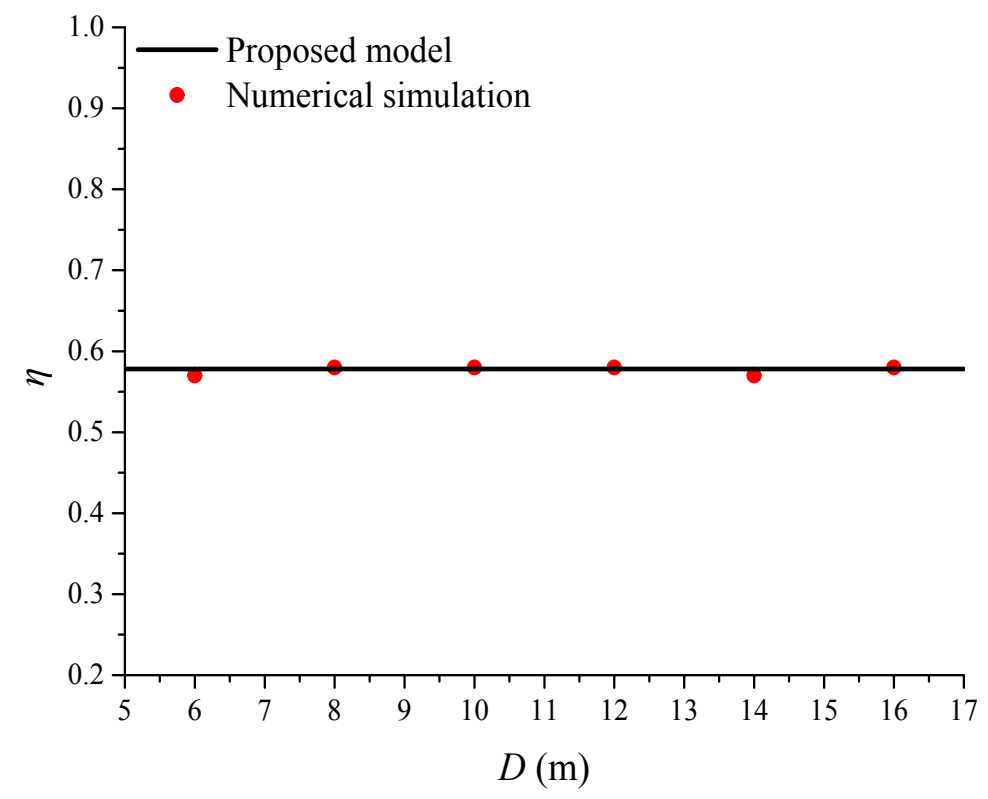

Fig. 10. Effects of $D$ on $\eta\left(C / D=0.5, \varphi=15^{\circ}\right)$.

\subsubsection{Effect of frictional angel $(\varphi)$}

For a certain value of $C / D$, the relationship between the partial failure ratio $\eta$ and the friction angle $\varphi$ is shown in Fig. 11. It can be seen that the partial failure ratio $\eta$ obtained by the proposed model first increases and then decreases gradually, while that obtained by the numerical simulation shows an increasing trend as a whole. When $\varphi<30^{\circ}$, the values of $\eta$ obtained by the proposed model are close to those obtained by the numerical simulation. However, the relatively large deviation occurs in the case of larger friction angle $\left(\varphi>30^{\circ}\right)$, which needs further investigation. 


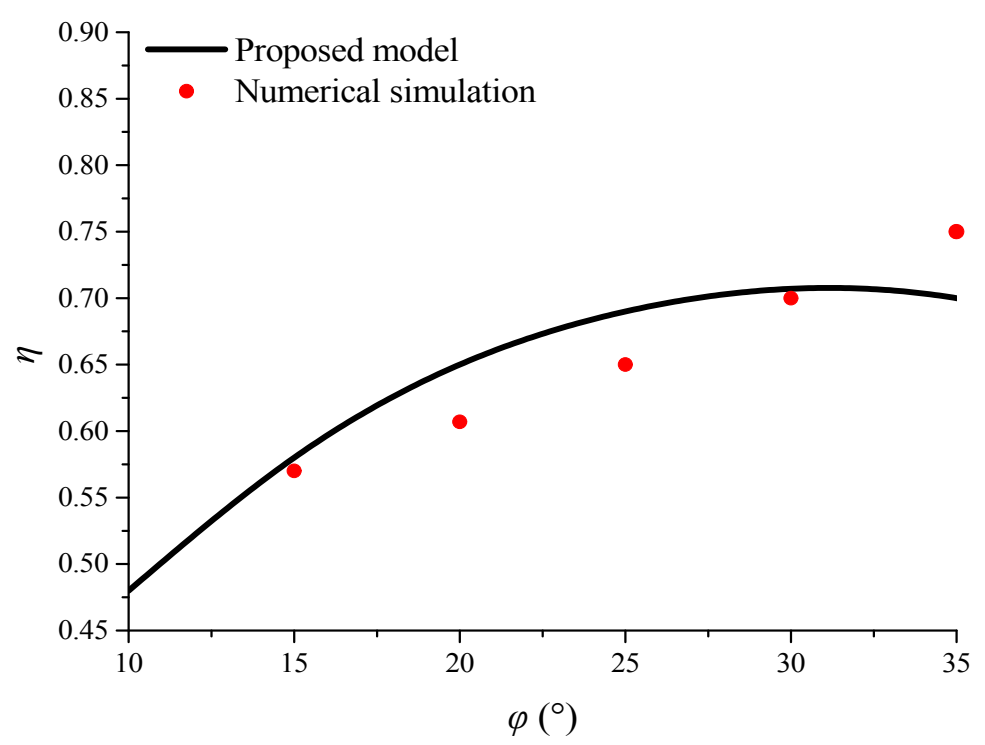

Fig. 11. Effects of $\varphi$ on $\eta(C / D=0.5)$.

\subsubsection{Effect of lateral pressure coefficient $\left(K_{0}\right)$}

The lateral pressure coefficient $K_{0}$, which is crucial to estimate the initial stresses, has a great influence on the stability of shallow tunnels (Chen et al. 2013; Lei et al., 2014; Qarmout et al. 2019). Fig. 12 gives the relationship between the partial failure ratio $\eta$ and the lateral pressure coefficient $K_{0}$. The values of soil parameters, tunnel diameter and cover depth are the same as case 9. According to Golpasand et al. (2018), the values of $K_{0}$ are in the range from 0.5 to 3.0. Note that, since the limit analysis method does not take the $K_{0}$ parameter into account, the theoretical results are constant and do not vary with the values of $K_{0}$. In addition, $\eta$ obtained by numerical simulation does not change with the increase of $K_{0}$, basically. Moreover, the theoretical solutions match well with the numerical solutions. 


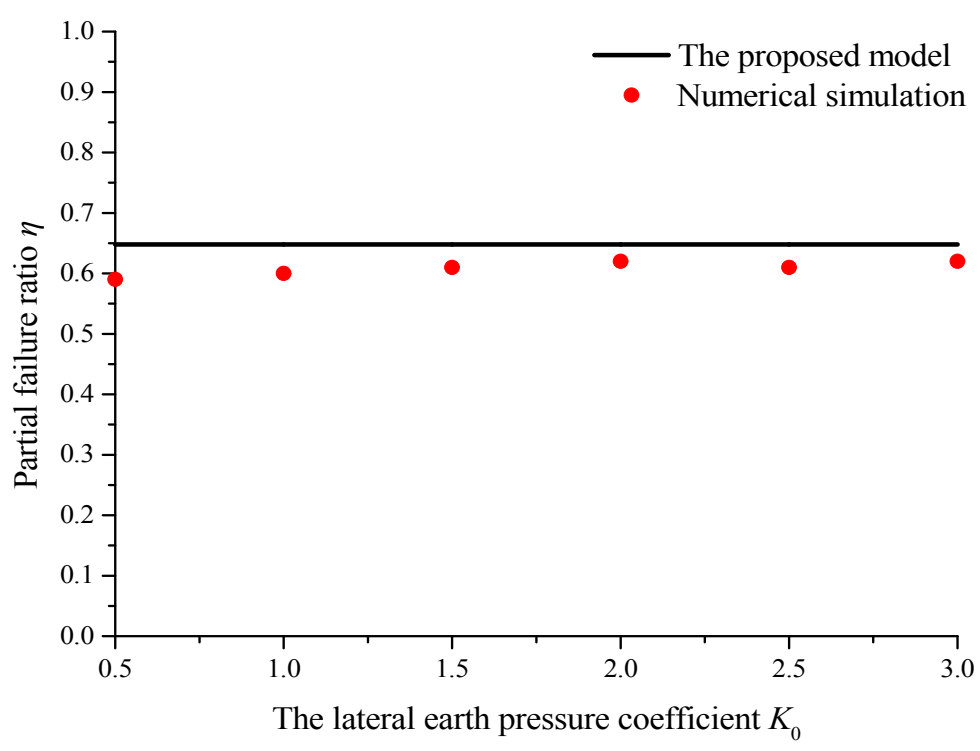

Fig. 12. Effects of $K_{0}$ on $\eta\left(C=3 \mathrm{~m}, D=6 \mathrm{~m}, \varphi=20^{\circ}\right)$.

\subsubsection{Effect of surcharge $\left(\sigma_{\mathrm{s}}\right)$}

The analysis of cover depth, tunnel diameter, friction angle and lateral pressure coefficient in the above sections is carried out under the assumption that the ground surcharge is zero. However, when tunneling below ground surface with existing surcharge, the movement and deformation of the stratum are different from those with stress free ground surface (Yamamoto et al., 2011; Ali et al., 2017; Wang et al., 2018). Fig. 13 indicates the variation of partial failure ratio $\eta$ as the increase of ground surcharge $\sigma_{\mathrm{s}}$. The values of soil parameters, tunnel diameter and cover depth are the same as case 9. As can be seen, the values of $\eta$ derived from the proposed model increase to a constant value and then remain unchanged (i.e. $\eta=1.0$ ) as ground surcharge $\sigma_{\mathrm{s}}$ further increases, while the numerical results increase relatively slowly. 


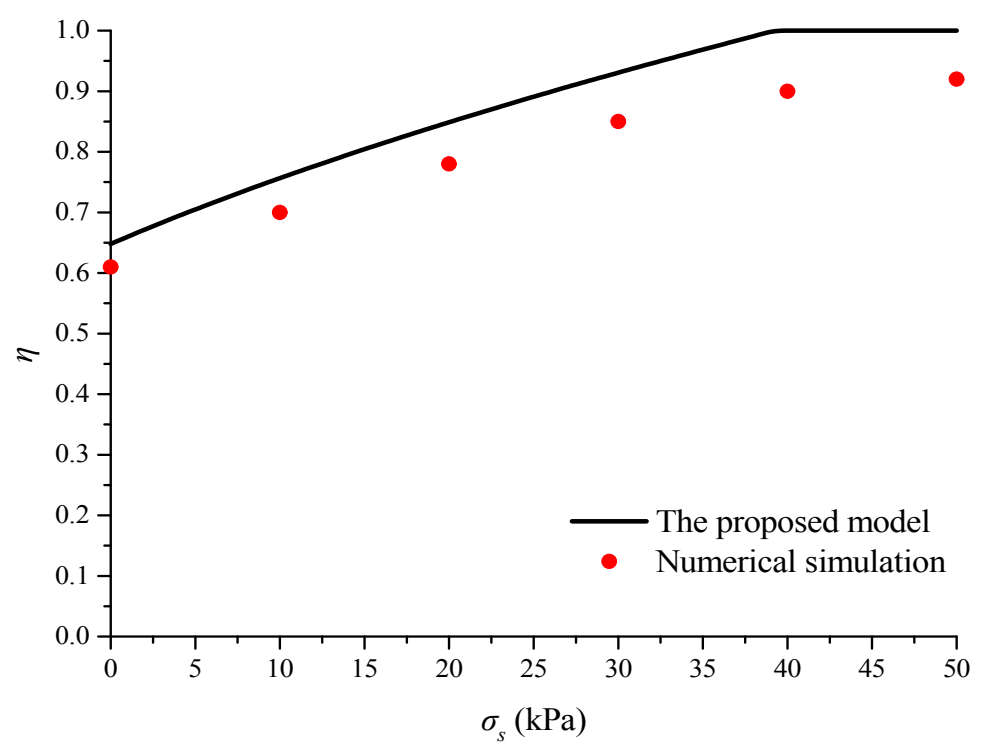

Fig. 13. Effects of $\sigma_{s}$ on $\eta\left(C=3 \mathrm{~m}, D=6 \mathrm{~m}, \varphi=20^{\circ}\right)$.

\subsection{Limit support pressure}

\subsubsection{Effect of cover depth $(C)$}

For a certain value of $D$, Fig. 14 shows the comparison of limit support pressure between the proposed model, numerical simulation and existing research results (Leca et al., 1990; Soubra et al.; $2008)$ in the sand with a small friction angle $\left(\varphi=15^{\circ}\right)$. In Fig. 14, the limit support pressures in blowout obtained by the theoretical model and numerical simulation increase with the increase of $C$. Combined with the analysis of Fig. 8, when the cover depth $C$ is less than the critical cover depth, the $\eta$ is less than 1.0 and the partial failure of the face occurs. When the cover depth $C$ reaches or exceeds the critical cover depth, the partial failure ratio $\eta$ is equal to 1.0 , that is, the failure mechanism of tunnel face evolves from partial failure to global failure. Note that, the upper bound theorem provides an unsafe estimate of the support pressure required to maintain face stability (higher or equal to that actually required for blow-out) (Mollon et.al 2010). Therefore, a smaller limit support pressure indicates a better solution. In case of $C=3 \mathrm{~m}\left(C / D=0.5, \varphi=15^{\circ}\right)$, the value of $\sigma_{\mathrm{T}}$ reduced by $7.2 \%$ with respect to the results of Soubra et al (2008), and the reduction attains $14 \%$ relative to the results presented by Leca et al (1990). The comparison results illustrate that the proposed model is suitable for calculating the case of partial failure. When $C=6 \mathrm{~m}(C / D=1.0)$, partial failure ratio $\eta$ is equal to 1.0 
and the limit support pressure in this paper is in agreement with that obtained by global failure model by Soubra et al (2008). The above analysis demonstrate that the proposed model in this paper not only can analyze the partial failure with better accuracy, but also can consider the situation of the global failure $(\eta=1)$, which indicates that the model has more extensive applicability.

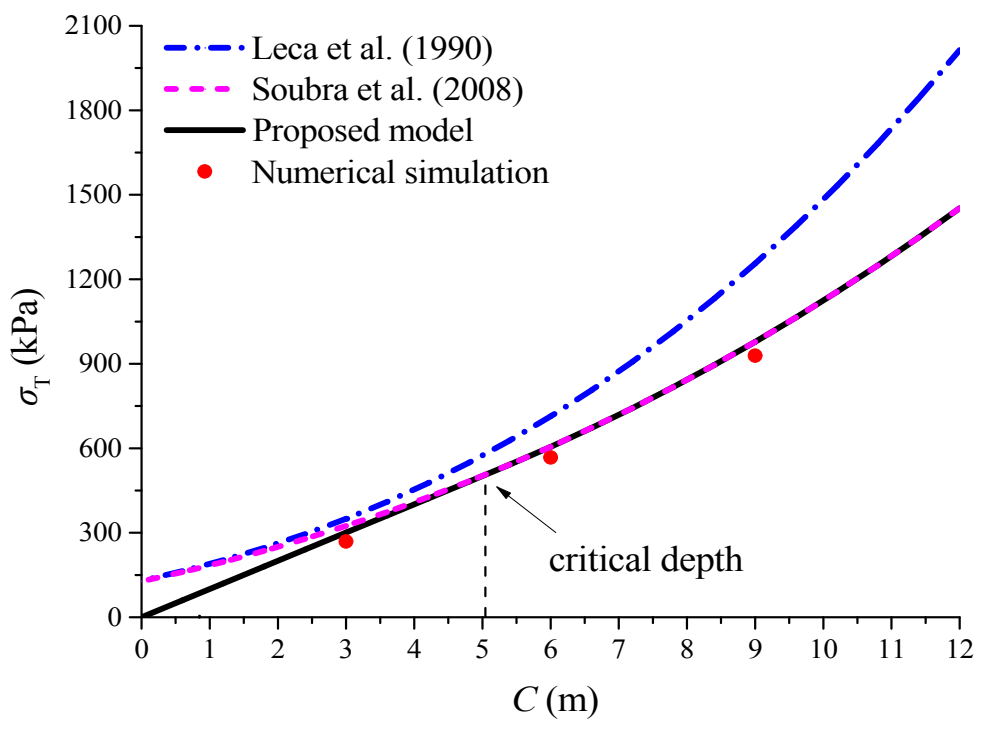

Fig. 14. Effects of $C$ on $\sigma_{\mathrm{T}}\left(D=6 \mathrm{~m}, \varphi=15^{\circ}\right)$.

\subsubsection{Effect of tunnel diameter $(D)$}

In the case of $C=3 \mathrm{~m}$, as tunnel diameter $D$ increases, Fig. 15 gives the results of limit support pressure provided by the proposed model and the existing approaches. It can be seen that the differences of results between the global failure model (Leca et al., 1990; Soubra et al.; 2008) and partial failure model are obvious in Fig. 15. The limit support pressure $\sigma_{\mathrm{T}}$ of the proposed model based on the assumption of partial failure remains unchanged, while that of the global failure model proposed by Leca et al. (1990) and Soubra et al. (2008) increases linearly. As shown in Fig. 15, the results of $\sigma_{\mathrm{T}}$ obtained by the proposed model is the closest to those obtained by numerical simulation. In addition, the reduction with respect to the results provided by Soubra et al. (2008) and Leca et al. (1990) can attain $41.2 \%$ and $42.9 \%$ when $D=16 \mathrm{~m}\left(C=3 \mathrm{~m}, \varphi=15^{\circ}\right)$, respectively. Therefore, it can be concluded that the partial failure in blow-out is more common than the global failure for the largediameter shallow tunnels, which has also proved in the literature of Li et al. (2009). 


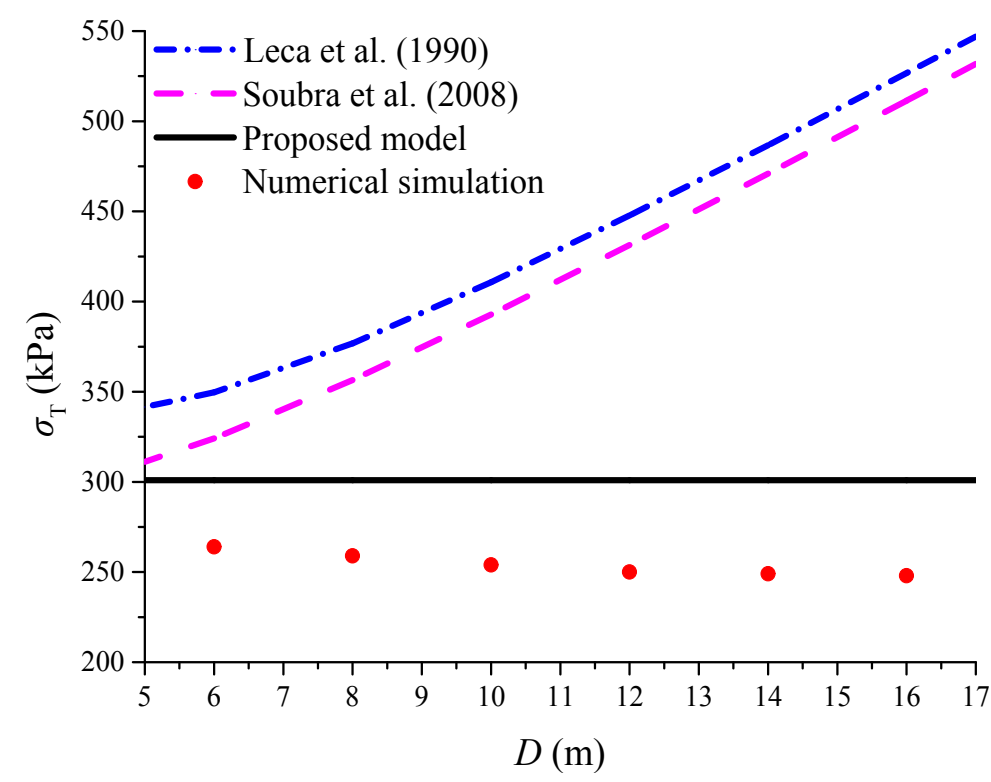

Fig. 15. Comparison of $\sigma_{\mathrm{T}}$ with the variation of Tunnel diameter $\left(C=3 \mathrm{~m}, \varphi=15^{\circ}\right)$.

For a constant value of $C / D$, the theoretical models mentioned in Fig. 16 demonstrate the same variation rule. The limit support pressure $\sigma_{\mathrm{T}}$ increases linearly as the tunnel diameter $D$ increases. Compared to the other theoretical models shown in Fig. 16, the results obtained by the proposed model gives better results since the present upper-bound solutions are smaller. For example, when $\mathrm{D}=12 \mathrm{~m}\left(C / D=0.5, \varphi=15^{\circ}\right)$, relative to the result presented by Leca et al (1990) and Soubra et al. (2008), the value of $\sigma_{\mathrm{T}}$ are improved (reduced) by $14 \%$ and $7.2 \%$, respectively.

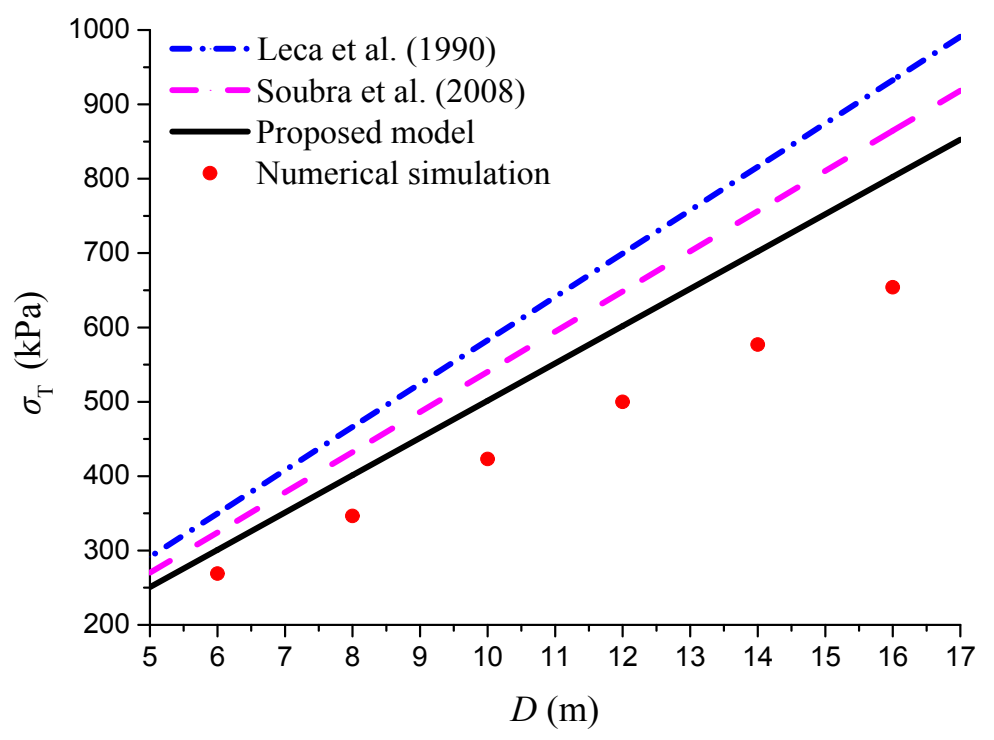

Fig. 16. Effects of $D$ on $\sigma_{\mathrm{T}}\left(C / D=0.5, \varphi=15^{\circ}\right)$. 


\subsubsection{Effect of frictional angel $(\varphi)$}

In the case where $C / D$ is constant , Fig. 17 presents the comparison of limit support pressure in various friction angle between the proposed model, numerical simulation and the existing approaches. It appears that the limit support pressure $\sigma_{\mathrm{T}}$ increase gradually with the increase of the friction angle regardless of the proposed model, the numerical simulation and the existing approaches. In Fig. 17, the single conical block model proposed by Leca et al. (1990) is more sensitive to $\varphi$ and its values of $\sigma_{\mathrm{T}}$ are larger than those of other mentioned models. In addition, compared with the multi-block model presented by Soubra et al. (2008), the limit support pressure obtained by the proposed model is smaller and closer to the results obtained by numerical simulation. Therefore, the limit support pressures obtained by the proposed model is improved. In the case of $\varphi=20^{\circ}(\mathrm{C}=3 \mathrm{~m}, \mathrm{D}=6 \mathrm{~m})$, the improvement (reduction) with respect to the results by Leca et al. (1990) and Soubra et al. (2008) are 15.2\% and 4.8\%, respectively. However, Fig. 17 also shows that the deviation between the theoretical solution and the numerical solution becomes greater as the friction angle increases.

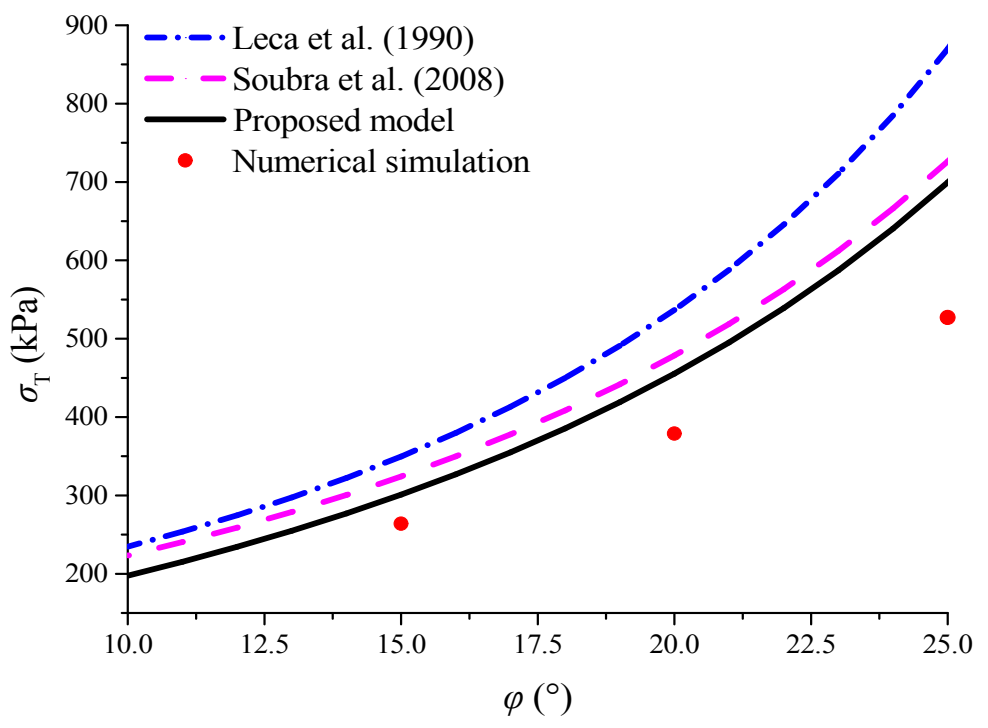

Fig. 17. Comparison of $\sigma_{\mathrm{T}}$ with the variation of friction $(C=3 \mathrm{~m}, D=6 \mathrm{~m})$.

\subsubsection{Effect of lateral pressure coefficient $\left(K_{0}\right)$}

The relationship between the limit support pressure ratio $P / P_{0}$ and lateral pressure coefficient $K_{0}$ 
is shown in Fig. 18(a). It seems that $P / P_{0}$ decreases with the increase of $K_{0}$. Fig. $18(\mathrm{~b})$ compares the limit support pressure $\sigma_{\mathrm{T}}$ provided by the proposed model, the existing approaches and the numerical simulation for various lateral pressure coefficients. The limit support pressures obtained by different values of $K_{0}$ are constant regardless of the analytical solutions and numerical solutions. In addition, compared with the results obtained by Leca et al. (1990) and Soubra et al. (2008), the limit support pressures $\sigma_{\mathrm{T}}$ presented by proposed model show smaller values and are closer to the numerical results, which means that the proposed model improves the existing model.

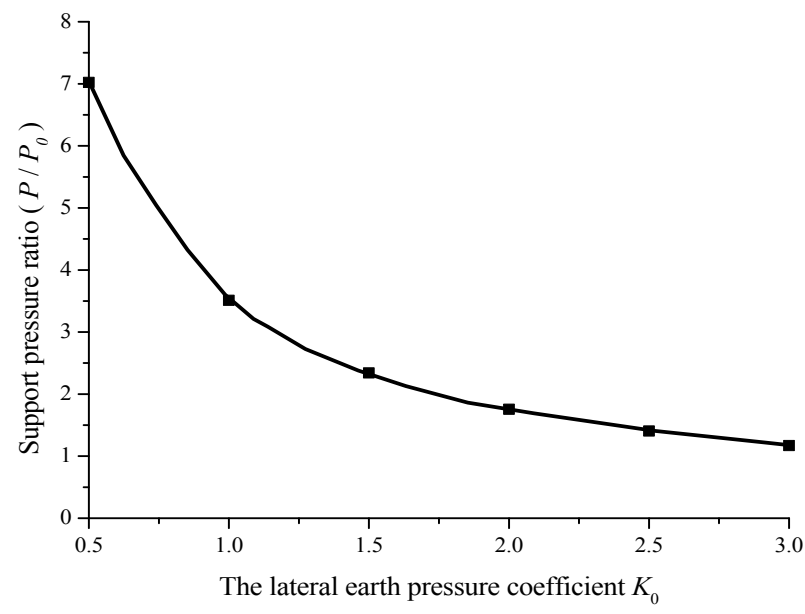

(a) Relationship between $K_{0}$ and $P / P_{0}$

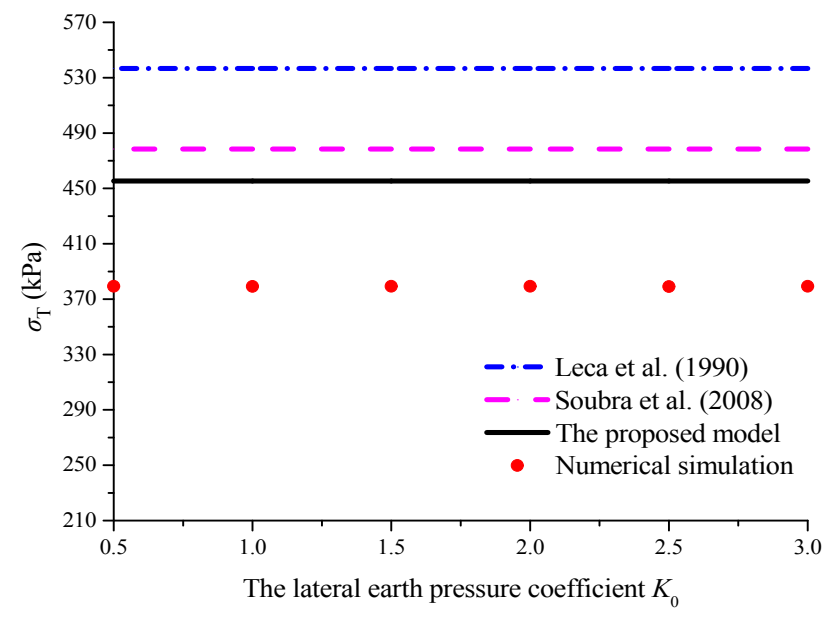

(b) Comparison of $\sigma_{\mathrm{T}}$ with the variation of $K_{0}$

Fig. 18. Effects of $K_{0}$ on $P / P 0$ and $\sigma_{\mathrm{T}}\left(C=3 \mathrm{~m}, D=6 \mathrm{~m}, \varphi=20^{\circ}\right)$.

Fig. 19 demonstrates the horizontal displacement curves within tunnel face in the limit state for various lateral pressure coefficient (i.e. $\left.K_{0}=0.5,1.0,1.5,2.0,2.5,3.0\right)$. The horizontal displacement within tunnel face are greatly affected by the values of $K_{0}$. When $K_{0}=0.5$, a relatively large displacement can be observed. With the increases of $K_{0}$, the horizontal displacement gradually decreases. Subsequently, the horizontal displacement increases as $K_{0}$ further increases. This variation can be more intuitively reflected in Fig. 20, which describes the relationship between the lateral pressure coefficient and the maximum displacement within tunnel face. In summary, the lateral 
pressure coefficient has a great influence on the displacement, but has almost no influence on the limit support pressure, which was also presented by Vermeer et al (2002).

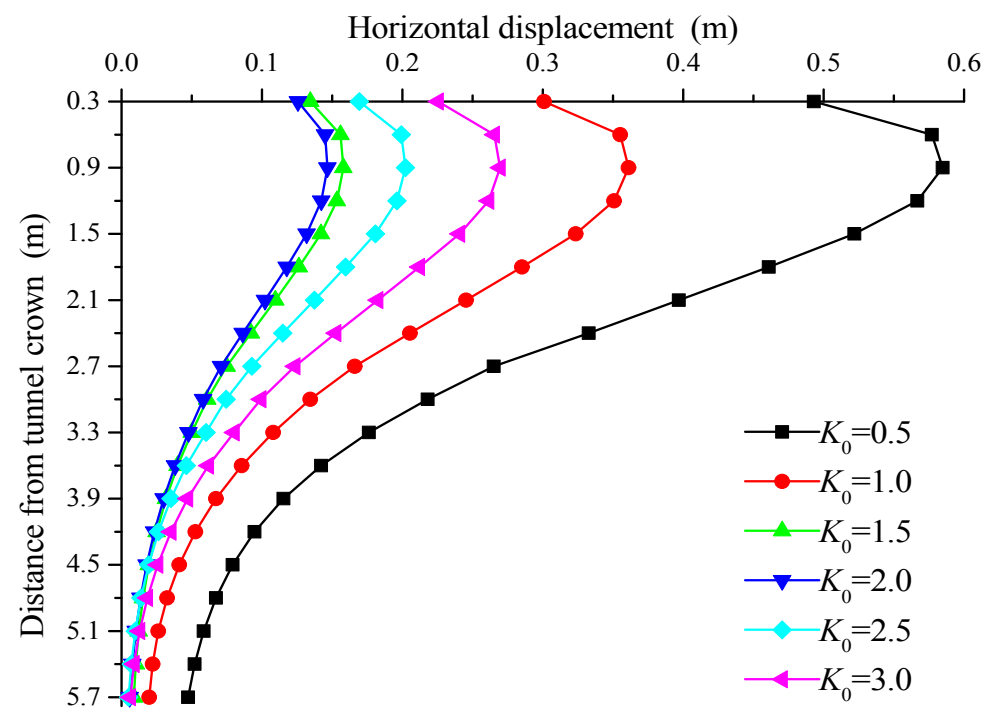

Fig. 19. Effects of $K_{0}$ on horizontal deformation $\left(C=3 \mathrm{~m}, D=6 \mathrm{~m}, \varphi=20^{\circ}\right)$.

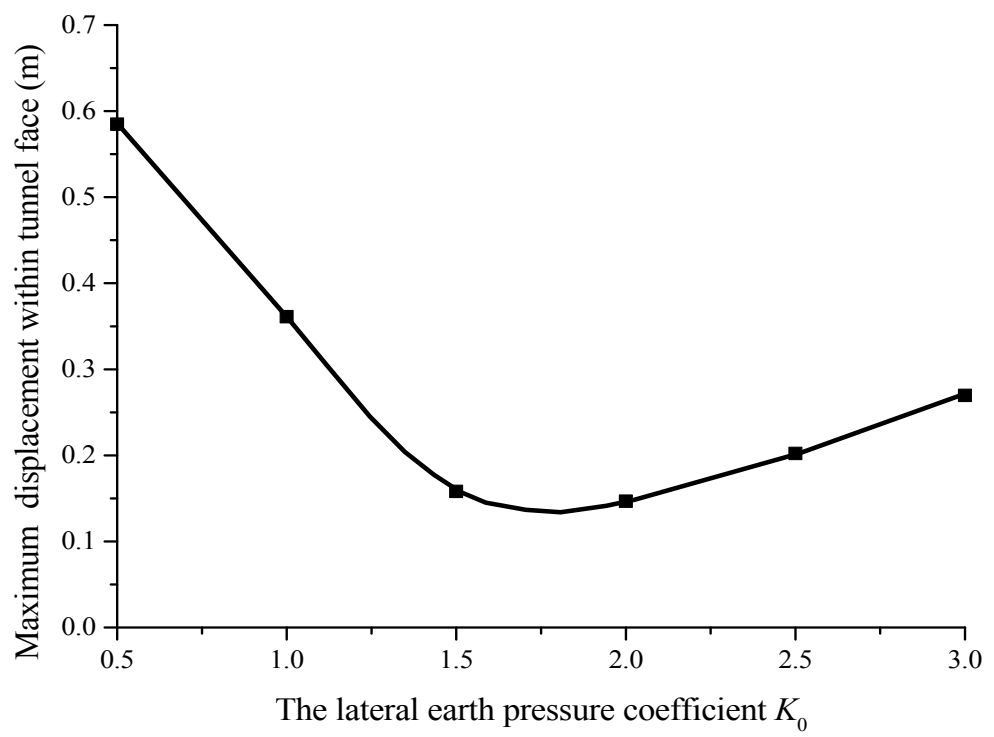

Fig. 20. Maximum displacement within tunnel face $\left(C=3 \mathrm{~m}, D=6 \mathrm{~m}, \varphi=20^{\circ}\right)$.

\subsubsection{Effect of surcharge $\left(\sigma_{\mathrm{s}}\right)$}

Fig. 21 presents the relationship between the limit support pressure and the surcharge. The values of soil parameters, tunnel diameter and cover depth are the same as case 9. With the increase of the surcharge applied on the ground, the limit support pressure $\sigma_{\mathrm{T}}$ increases linearly, which means the 
surcharge has a significant impact on the $\sigma_{\mathrm{T}}$-value. Compared with the theoretical models mentioned in the Fig. 21, the results obtained by the proposed model in this paper are the closest to the numerical solutions, especially for a small ground surcharge. Moreover, as the value of $\sigma_{\mathrm{s}}$ further increases, the results of proposed model considering the partial failure are more and more consistent with those of the global failure model presented by Soubra et al (2008).

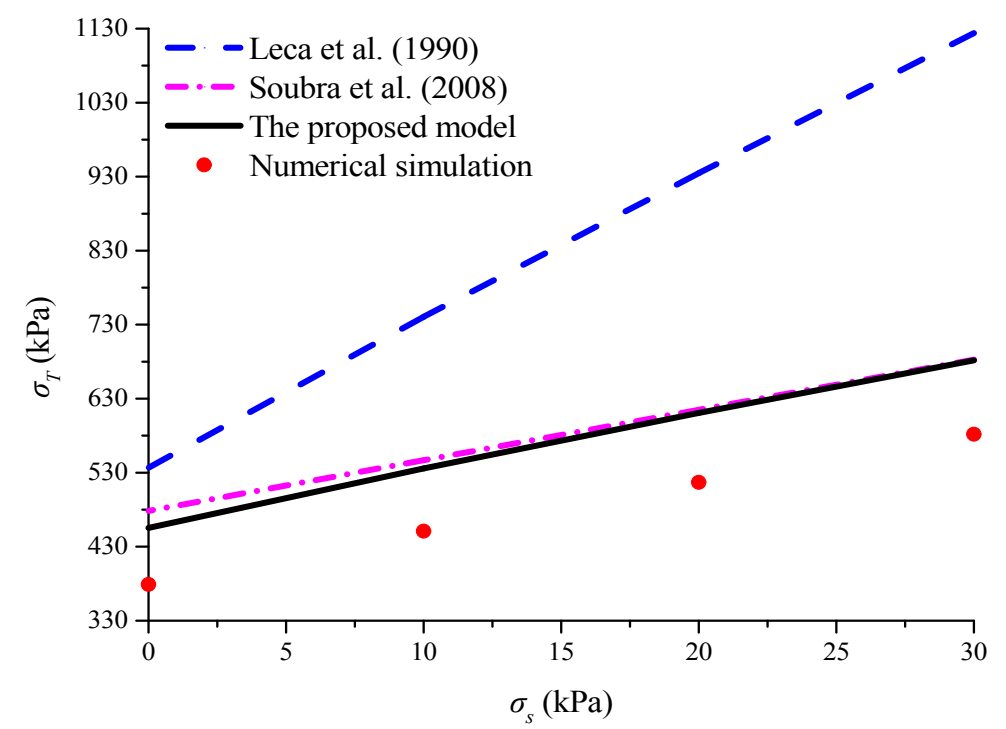

Fig. 21. Comparison of $\sigma_{\mathrm{T}}$ with the variation of surcharge $\left(C=3 \mathrm{~m}, D=6 \mathrm{~m}, \varphi=20^{\circ}\right)$.

\section{Conclusions}

The paper presents an analytical model of blow-out for shallow tunnels in sand under drained condition considering the partial failure within tunnel face based on the upper bound theorem. A series of numerical simulations are carried out to analyse the influence of the cover depth, tunnel diameter and the friction angle on the partial failure ratio and limit support pressure. The main conclusions are as follows:

(1) Compared with the classical solutions, the analysis shows that the proposed model gives better results in solving the passive partial failure ratio and the limit support pressure.

(2) The cover depth of the tunnel is of great importance to the partial failure ratio and limit 
support pressure. The greater the cover depth ratio, the greater the partial failure ratio. When the cover depth ratio exceeds 1.0, the failure mechanism of tunnel face is no longer the partial failure, but shows the characteristic of global failure. Under the condition of constant tunnel diameter, the limit support pressure increases with the increase of the cover depth.

(3) Contrary to the cover depth, the tunnel diameter has little effect on the range of blow-out area and the limit support pressure of tunnel face. The blow-out area mainly occurs in the upper part of tunnel face. In the case of the same cover depth, the larger the tunnel diameter, the smaller the partial failure ratio, while the limit support pressure tends to be constant.

(4) It is worthwhile to note that friction angle is critical for the partial failure ratio and limit support pressure. In the limit state, as the friction angle increases, the failure range of tunnel face expands continuously, and the maximum outcrop point of the ground approaches toward the tunnel face. Meanwhile, the limit support pressure continues to increase. However, the deviation between the proposed model and the numerical simulation also becomes more obvious with the friction angle increases, which needs further investigations.

(5) The lateral pressure coefficient is one of the most important parameters in geotechnical engineering. However, it affects the deformation and the limit support pressure ratio within the face rather than the limit support pressure. As the lateral pressure coefficient increases, the limit support pressure ratio decreases gradually, while the deformation within the face decreases at first and then increases. Besides, it seems that the change of lateral pressure coefficient does not have a remarkable effect on the partial failure ratio.

(6) The ground surcharge affects both the deformation of the stratum and tunnel face stability. The limit support pressure increases linearly with the increase of ground surcharge, which means the value of surcharge greatly affects the tunnel face stability. In addition, the partial failure ratio increases at first with the increase of ground surcharge and then tends to be constant. 


\section{References}

Aksoy, C.O., Onargan, T., 2010. The role of umbrella arch and face bolt as deformation preventing support system in preventing building damages. Tunn. Undergr. Space Technol. 25, 553-559.

Ali, A., Lyamin, A. V., Huang, J., Sloan, S. W., Cassidy, M.J., 2017. Undrained stability of a single circular tunnel in spatially variable soil subjected to surcharge loading. Comput. Geotech. 84, $16-27$.

Anagnostou, G., Kovári, K., 1996. Face stability condition with earth pressure balanced shields. Tunn. Undergr. Space Technol. 11 (2), 165-173.

Anagnostou, G., Perazzelli, P., 2015. Analysis method and design charts for bolt reinforcement of the tunnel face in cohesive-frictional soils. Tunn. Undergr. Space Technol. 47, 162-181.

Broere, W., 2001. Tunnel face stability and new CPT applications. PhD Thesis, Delft University of Technology. The Netherlands: Delft University Press.

Broms, B.B., Bennermark, H., 1967. Stability of clay in vertical openings. Am. Soc. Civ. Eng. - J. Soil Mech. Found. Div. 193 (1), 71-94.

Chen, R.P., Li, J., Kong, L.G., Tang, L.J., 2013. Experimental study on face instability of shield tunnel in sand. Tunn. Undergr. Space Technol. 33, 12-21.

Chen, R.P., Qi, L.Z., Tang, L.J., Zhou, B.S., 2013. Study of limit supporting force of excavation face's passive failure of shield tunnels in sand. Chin. J. Rock Mech. Eng. 32 (suppl 1), 28772882 (in Chinese).

Chen, R.P., Yin, X.S., Tang, L.J., Chen, Y.M., 2018. Centrifugal model tests on face failure of earth pressure balance shield induced by steady state seepage in saturated sandy silt ground. Tunn. Undergr. Space Technol. 81, 315-325. 
Davis, E.H., Gunn, M.J., Mair, R.J., Seneviratne, H.N., 1980. The stability of shallow tunnels and underground openings in cohesive material. Geotechnique. 30 (4), 397-416.

Dias D., Janin J P., Soubra A H., Kastner, R., 2008. Three-Dimensional Face Stability Analysis of Circular Tunnels by Numerical Simulations. In: Proceedings of GeoCongress: Characterization, Monitoring, and Modeling of GeoSystems. Louisiana: ASCE, pp. 886-893.

Ding, W., Liu, K., Shi, P., Li, M., Hou, M., 2019. Face stability analysis of shallow circular tunnels driven by a pressurized shield in purely cohesive soils under undrained conditions. Comput. Geotech.107, 110-127.

Fang, Q., Zhang, D.L., Wong, L.N.Y., 2012. Shallow tunnelling method (STM) for subway station construction in soft ground. Tunn. Undergr. Space Technol. 29(3), 10-30.

Fang, Q., Zhang, D., Li, Q. Q., Wong, L. N. Y., 2015. Effects of twin tunnels construction beneath existing shield-driven twin tunnels. Tunn. Undergr. Space Technol .45, 128-137.

Gioda, G., Swoboda, G., 1999. Developments and applications of the numerical analysis of tunnels in continuous media. Int. J. Numer. Anal. Methods. Geomech. 23, 1393-1405.

Golpasand, M.R.B., Do, N.A., Dias, D., Nikudel, M.R., 2018. Effect of the lateral earth pressure coefficient on settlements during mechanized tunneling. Geomech.Eng. 16(6), 643-654.

Han, K.H., Zhang, C.P., Zhang, D.L., 2016. Upper-bound solutions for the face stability of a shield tunnel in multilayered cohesive-frictional soils. Comput. Geotech. 79, 1-9.

Horn, N., 1961. Horizontal earth pressure on the vertical surfaces of the tunnel tubes. In: National Conference of the Hungarian Civil Engineering Industry, Budapest, November, pp.7-16 (in German).

Ibrahim, E., Soubra, A.H., Mollon, G., Raphael, W., Dias, D., Reda, A., 2015. Three-dimensional 
face stability analysis of pressurized tunnels driven in a multilayered purely frictional medium. Tunn. Undergr. Space Technol. 49, 18-34.

Jancsecz, S., Steiner, W., 1994. Face support for a large mix-shield in heterogeneous ground conditions. In: Proc. Tunneling '94. London, Institution of Mining and Metallurgy, London, pp. $531-550$.

Jing, L.J., Li, J.B., Yang, C., Chen, S., Zhang, N., Peng, X.X., 2019. A case study of TBM performance prediction using field tunnelling tests in limestone strata. Tunn. Undergr. Space Technol. 83:364-372.

Khezri, N., Mohamad H., HajiHassani, M., Fatahi B., 2015. The stability of shallow circular tunnels in soil considering variations in cohesion with depth. Tunn. Undergr. Space Technol. 49, 230240.

Klotz, U., Vermeer, P.A., Klotz, C., Möller, S., 2006. A 3D finite element simulation of a shield tunnel in weathered Singapore Bukit Timah Granite. Tunn. Undergr. Space Technol. 21(3), 272272.

Leca, E., Dormieux L., 1990. Upper and lower bound solutions for the face stability of shallow circular tunnels in frictional material. Géotechnique, 40 (4), 581-606.

Lei, M.F., Peng, L.M., Shi, C.H., 2014. Calculation of the surrounding rock pressure on a shallow buried tunnel using linear and nonlinear failure criteria. Auto. Construct. 37, 191-195.

Li, B., Hong, Y., Gao, B., Qi, T. Y., Wang, Z. Z., Zhou, J. M., 2015. Numerical parametric study on stability and deformation of tunnel face reinforced with face bolts. Tunn. Undergr. Space Technol. 47, 73-80.

Liao, S.M., Liu, J.H., Wang, R.L., Li, Z.M., 2009. Shield tunneling and environment protection in 
Shanghai soft ground. Tunn. Undergr. Space Technol. 24 (4), 454-465.

Li, Y., Emeriault, F., Kastner, R., Zhang, Z.X., 2009. Stability analysis of large slurry shield-driven tunnel in soft clay. Tunn. Undergr. Space Technol. 24, 472-481.

Li, Y., Zhang Z.X., Zhang G. J., 2007. Laboratory study on face stability mechanism of slurry shields. Chin. J. Geo. Eng. 29 (7), 1074-1079 (in Chinese).

Maidl, B., Thewes, M., Maidl, U., 2013. Handbook of Tunnel Engineering. Structures and Methods, vol. I. Wilhelm Ernst \& Sohn, Berlin.

Mollon, G., Dias, D., Soubra, A.H., 2011. Rotational failure mechanisms for the face stability analysis of tunnels driven by a pressurized shield. Int. J. Numer. Anal. Methods Geomech. 35(12), 1363 1388.

Mollon, G., Dias, D., Soubra, A.H., 2010. Face stability analysis of circular tunnels driven by a pressurized shield. J. Geotech. Geoenviron. Eng. 136(1), 215-229.

Mollon, G., Dias, D., Soubra, A.H., 2013. Continuous velocity fields for collapse and blowout of a pressurized tunnel face in purely cohesive soil. Int. J. Numer. Anal. Methods Geomech. 37, $2061-2083$.

Murayama, S., Endo, M., Hashiba, T., Yamamoto, K., Sasaki, H. (Eds.), 1966. Geotechnical aspects for the excavating performance of the shield machines. In: The 21st Annual Lecture in Meeting of Japan Society of Civil Engineers.

Ocak, I., 2008. Control of surface settlements with umbrella arch method in second stage excavations of Istanbul Metro. Tunn. Undergr. Space Technol. 23, 674-681.

Oke, J., Vlachopoulos, N., Diederichs, M.S., 2014. Numerical analyses in the design of umbrella arch systems. J. Rock Mech. Geotech. Eng. 6 (6), 546-564. 
Patil, M., Choudhury, D., Ranjith P.G., Zhao J., 2018. Behavior of shallow tunnel in soft soil under seismic conditions. Tunn. Undergr. Space Technol. 82, 30-38.

Pan, Q., Dias, D., 2017. Safety factor assessment of a tunnel face reinforced by horizontal dowels. Eng. Struct. 142, 56-66.

Qarmouta, M., Königa, D., Gussmannb, P., Thewesc, M., Schanz, T., 2019.Tunnel face stability analysis using Kinematical Element Method. Tunn. Undergr. Space Technol. 85, 354-367.

Senent, S., Mollon, G., Jimenez, R., 2013. Tunnel face stability in heavily fractured rock masses that follow the Hoek-Brown failure criterion. Int. J. Rock Mech. Min. Sci. 60,440-451.

Soubra, A.H., 2000. Three-dimensional face stability analysis of shallow circular tunnels. In:

Proceedings of International Conference on Geotechnical and Geological Engineering, Melbourne, Australia, pp. 19-24.

Soubra, A.H., Dias, D., Emeriault, F., Kastner, R., 2008. Three-dimensional face stability analysis of circular tunnels by a kinematical approach. Geotechnical Special Publication 894-901.

Sterpi, D., Rizzo, F., Renda, D., Aguglia, F., Zenti, CL., 2013. Soil nailing at the tunnel face in difficult conditions: a case study. Tunn. Undergr. Space Technol. 38,129-139.

Subrin, D., Wong, H., 2002. Tunnel face stability in frictional material: a new 3D failure mechanism. Mecanique. 330(7), 513-519.

Vermeer, P.A., Ruse, N., Marcher, T., 2002. Tunnel heading stability in drained ground. Felsbau 20 (6), 8-18.

Wang, H. N., Chen, X.P., Jiang, M. J., Song, F., Wu, L., 2018. The analytical predictions on displacement and stress around shallow tunnels subjected to surcharge loadings. Tunn. Undergr. Space Technol. 71, 403-427. 
Wong, K.S., Ng, C.W.W., Chen, Y.M., Bian, X.C., 2009. Three-dimensional analysis of passive failure of circular tunnel face in layered ground. In: Proceedings of the 2nd International Conference on Computational Methods in Tunnelling. Bochum, German: Ruhr University Bochum, pp. 841-848.

Wong, K.S., Ng, C.W.W., Chen, Y.M., Bian, X.C., 2012. Centrifuge and Numerical Investigation of Passive Failure of Tunnel Face in Sand. Tunn. Undergr. Space Technol. 28 (3): 297-303.

Yamamoto, K., Lyamin, A.V., Wilson, D.W., Sloan, S.W., Abbo, A.J., 2011. Stability of a circular tunnel in cohesive-frictional soil subjected to surcharge loading. Comput. Geotech. 38, 504-514. Yoo, Chungsik., 2002. Finite-element analysis of tunnel face reinforced by longitudinal pipes. Comput. Geotech. 29 (1), 73-94.

Zhang, C.P., Han, K.H., Zhang, D.L., 2015. Face stability analysis of shallow circular tunnels in cohesive-frictional soils. Tunn. Undergr. Space Technol. 50, 345-357.

Zhou, C., Ding, L.Y., He. R., 2013. PSO-based Elman neural network model for predictive control of air chamber pressure in slurry shield tunneling under Yangtze River. Autom. Constr. 36, 208217.

Zhang, Z.Q., Li, H.Y., Liu, H.Y., Li, G.J., Shi, X.Q., 2014. Load transferring mechanism of pipe umbrella support in shallow-buried tunnels. Tunn. Undergr. Space Technol. 43, 213-221. 